TITLE:

\title{
Hydrodynamics and heat transfer characteristics of oil-in-water emulsion droplets impinging on hot stainless steel foil
}

\section{$\operatorname{AUTHOR}(\mathrm{S}):$}

Fujimoto, Hitoshi; Obana, Wataru; Ashida, Masayoshi; Hama, Takayuki; Takuda, Hirohiko

\section{CITATION:}

Fujimoto, Hitoshi ... [et al]. Hydrodynamics and heat transfer characteristics of oil-in-water emulsion droplets impinging on hot stainless steel foil. Experimental Thermal and Fluid Science 2017, 85: 201-212

ISSUE DATE:

2017-07-01

URL:

http://hdl.handle.net/2433/224957

\section{RIGHT:}

(c) 2017. This manuscript version is made available under the CC-BY-NC-ND 4.0 license

http://creativecommons.org/licenses/by-nc-nd/4.0/; The full-text file will be made open to the public on 01 July 2019 in accordance with publisher's 'Terms and Conditions for Self-Archiving'.; この論文は出版社版でありません。引用の際に は出版社版をご確認ご利用ください。; This is not the published version. Please cite only the published version. 
Hydrodynamics and Heat Transfer Characteristics of Oil-in-Water Emulsion Droplets Impinging on Hot Stainless Steel Foil

\section{Hitoshi Fujimoto ${ }^{\mathrm{a}}$, Wataru Obana ${ }^{\mathrm{a}, 1}$, Masayoshi Ashidaa ${ }^{\mathrm{a}}$, Takayuki Hama ${ }^{\mathrm{a}}$, and Hirohiko Takuda ${ }^{a}$}

${ }^{a}$ Department of Energy Science and Technology, Graduate School of Energy Science, Kyoto University, Yoshida-honmachi, Sakyo-ku, Kyoto 606-8501, Japan

Corresponding author. Hitoshi Fujimoto

\section{Abstract}

The hydrodynamics and heat transfer characteristics of oil-in-water $(\mathrm{O} / \mathrm{W})$ emulsion droplets impinging on a hot stainless steel foil were investigated experimentally. A two-directional flash-photography technique was adopted to track the time evolution of the droplet shapes. The temperature history of the foil during the collision with the droplets was also measured using a high-speed infrared thermometer. The main objective was to investigate the effects of varying the solid temperature and oil concentration on the heat transfer characteristics. The foil temperature was varied from 140 to $470{ }^{\circ} \mathrm{C}$, and the oil concentration in the $\mathrm{O} / \mathrm{W}$ emulsion was varied to be 1,5 , and $15 \mathrm{wt} \%$. The impact velocity of the droplets was $1.0 \mathrm{~m} / \mathrm{s}$, and the pre-impact diameter of the emulsion droplets was approximately $2.5 \mathrm{~mm}$ for oil concentrations of 1 and $5 \mathrm{wt} \%$

\footnotetext{
1 Present address: JFE Steel Corporation, 1 Kawasaki-cho, Chuo-ku, Chiba 260-0835, Japan
} 
and $2.4 \mathrm{~mm}$ for the oil concentration of $15 \mathrm{wt} \%$. Water and base oil were also used as test liquids for reference. Because the boiling temperature of the oil $\left(\sim 300{ }^{\circ} \mathrm{C}\right)$ is considerably higher than that of water and the thermal conductivity of the base oil is appreciably smaller than that of water, the hydrodynamics and boiling phenomena of droplets are strongly dependent on not only the solid temperature but also the oil concentration. In the nucleate boiling regime, the heat removal increases with the solid temperature, reaches a peak, and then decreases; the peak heat removal depends on the oil concentration. The heat transfer characteristics are discussed in detail in terms of the liquid motion, flow boiling, and local concentration of the oil phase.

Keywords: oil-in-water emulsion, droplet dynamics, flow visualization, boiling heat transfer

\section{Nomenclature}
A $\quad$ area, $\mathrm{m}^{2}$
c specific heat, $\mathrm{J} /(\mathrm{kg} \cdot \mathrm{K})$
$d \quad$ foil thickness, $\mathrm{m}$
$d_{p} \quad$ pre-impact diameter of droplet, $\mathrm{m}$
$N \quad$ number of runs
$q \quad$ heat flux, $\mathrm{W} / \mathrm{m}^{2}$
$\bar{q} \quad$ time-averaged heat flux, $\mathrm{W} / \mathrm{m}^{2}$
$t \quad$ time, $\mathrm{s}$
$T_{m} \quad$ measured foil temperature, ${ }^{\circ} \mathrm{C}$
$T_{w} \quad$ initial foil temperature, ${ }^{\circ} \mathrm{C}$
$v \quad$ impact velocity of droplet, $\mathrm{m} / \mathrm{s}$ 


\title{
Greek symbols
}

\author{
$\Delta T \quad$ temperature decrease ${ }^{\circ} \mathrm{C}$ \\ $\lambda \quad$ thermal conductivity, $\mathrm{W} /(\mathrm{m} \cdot \mathrm{K})$ \\ $\rho \quad$ substrate density, $\mathrm{kg} / \mathrm{m}^{3}$ \\ $\sigma \quad$ error range, ${ }^{\circ} \mathrm{C}$
}

\section{Introduction}

A mixture of two kinds of immiscible liquids, in which one liquid is dispersed in the other liquid, is called an emulsion. Oil and water, with small amounts of surfactants, can form two types of emulsions depending on the mixing ratio of these liquids. One type is the water-in-oil emulsion, wherein oil is the continuous phase and small water droplets are dispersed in the oil. The other is the oil-in-water $(\mathrm{O} / \mathrm{W})$ emulsion, wherein oil droplets are dispersed in water. Fig. 1 shows a schematic of the $\mathrm{O} / \mathrm{W}$ emulsion. Water and oil phases are combined using a surfactant that contains both hydrophilic and lipophilic groups [1]. The small oil droplets in the emulsion are kept in a metastable dispersed state because of the presence of the surfactant.

The lubricating properties of emulsion liquids have been extensively studied by researchers and engineers in the field of tribology [1-3]. Emulsions composed of water and oil are employed as the metalworking fluid in various operations such as rolling, cutting, ironing, and grinding [1-5]. In steel-making industries, spray jet impingement of $\mathrm{O} / \mathrm{W}$ emulsions is widely used in cold rolling mills for lubrication and cooling. O/W emulsions are also utilized in hot and cold rolling mills in aluminum-making industries. In these processes, the oil phase in the $\mathrm{O} / \mathrm{W}$ emulsion works as a lubricant for reducing the frictional forces between work rolls and rolled materials. O/W emulsions also 
remove the frictional and processing heat generated by the plastic deformation of rolled materials. This cooling process is of great importance for preventing "heat scratches" formed on the material surfaces [4] and reducing unwanted local thermal expansion/contraction of work rolls. The heat transfer characteristics of emulsion spray jets impinging on a hot solid play an important role in determining engineering demands [5]. However, to date, cooling conditions have been empirically determined without understanding the flow motion of the relevant emulsions in detail.

The impact of droplets impinging on a hot solid is an important component of the process of spray jet impingement. In conjunction with their hydrodynamic behavior, the heat transfer characteristics of individual droplets on a hot solid must be well understood to build more accurate numerical models for predicting heat transfer rates. Numerous studies have been conducted on droplet-substrate collisions, and some excellent reviews have also been published [6-11]. Several research groups have measured the conjugate heat transfer of droplets and a hot substrate, incorporating photographic observation of the liquid motion, using single-component liquids like water or fuel [12-16]. However, an extensive literature survey produced no similar works that have been published on $\mathrm{O} / \mathrm{W}$ emulsions. Addressing this deficiency is the primary objective of the present study.

Prior fundamental works reported that several parameters significantly influence the evaporation behavior of emulsion droplets on a hot solid. Some of the prior works studied water-in-fuel emulsions for combustion engine applications. Kimoto et al. [17] observed the vaporizing behavior of emulsified fuel droplets on a hot brass surface. They found that the size of the water droplets in the emulsion played an important role in determining the characteristics of the boiling phenomena of the droplets. Avedisian and Fatehi [18] reported on the evaporation characteristics of water-in-heptane and water-in-decane emulsion droplets with diameters of approximately $3 \mathrm{~mm}$ on a hot 
polished stainless steel surface at $292-407{ }^{\circ} \mathrm{C}$. The droplet evaporation depended significantly on the temperature of the solid and the emulsion components.

In another prior work related to the present study, Prunet-Foch et al. [19] investigated the impact of 2.7-mm-diameter $\mathrm{O} / \mathrm{W}$ emulsion droplets impinging at a velocity of $3.5 \mathrm{~m} / \mathrm{s}$ onto a stainless steel surface. They showed that the splash and fingering phenomena of emulsion droplets differ from those of water and are significantly influenced by the roughness of the solid and the type of organic coating on the solid surface. These researchers discussed their results not only from the hydrodynamic aspect, but also from the physicochemical aspect, considering that the emulsion has two constituents with different adherence characteristics in the dispersed system.

Takashima and Shiota [20] studied the evaporation characteristics of O/W emulsion droplets on a hot brass surface and reported that the evaporation behavior of the droplets depended not only on the mixing ratio of the water and oil but also on the solid temperature. Nagai et al. [21] investigated the deformation and oil adhesion characteristics of an $\mathrm{O} / \mathrm{W}$ emulsion impinging on a hot aluminum solid in a die casting process. They found that the Leidenfrost temperature was not strongly affected by the droplet impact velocity but was significantly affected by the oil concentration and liquid temperature. Furthermore, they clarified that liquid-solid contact certainly occurred even at surface temperatures higher than the Leidenfrost temperature.

These works reveal that the evaporation/boiling behavior and flow motion of emulsion droplets on a hot solid is affected by various factors such as the emulsion components, oil concentration, and solid surface conditions, including solid temperature. However, the published literature includes few experimental works on emulsion droplet impact characteristics. Therefore, more studies are needed to 
understand the fundamental principles of the heat transfer characteristics between a hot solid and emulsion droplets.

In the present study, the hydrodynamics and heat transfer characteristics of $\mathrm{O} / \mathrm{W}$ emulsion droplets impinging on a hot stainless steel foil were studied by means of flash photography and transient foil temperature measurements. In the experiments, a two-directional flash-photography technique was adopted for observing the motion of the droplets [22]. The time history of the solid temperature during the collision with the droplets was measured by a high-speed quantum-type infrared thermometer from behind the foil.

The oil concentration in the emulsion and the solid temperature were systematically varied. The composition of the base oil was $95.0 \mathrm{wt} \%$ mineral oil and $5.0 \mathrm{wt} \%$ emulsifier, which is commonly used in actual metal sheet-rolling processes. The oil concentration in the $\mathrm{O} / \mathrm{W}$ emulsion was varied to be 1,5 , and $15 \mathrm{wt} \%$, and water and base oil droplets were also tested for reference. The boiling temperature of the base oil $\left(\sim 300{ }^{\circ} \mathrm{C}\right.$ ) is considerably higher than that of water, and the thermophysical properties of the test liquids are strongly dependent on the oil concentration, as listed in Table 1. A stainless steel foil with a thickness of $0.1 \mathrm{~mm}$ was used as the test substrate. The initial solid temperature was varied from 140 to $470{ }^{\circ} \mathrm{C}$. It is found that the deformation behavior and boiling phenomena of the emulsion droplets are strongly influenced by the solid temperature and oil concentration. The heat transfer characteristics are discussed in detail in terms of the liquid motion, flow boiling, and local oil concentration.

\section{Experiments}

\subsection{Experimental apparatus and measurement procedure}

Fig. 2 shows a schematic diagram of the experimental apparatus used to observe the 
impact phenomena of emulsion droplets on the heated surface and the time variation of the solid temperature during the collisions with the droplets. The setup is composed of a syringe unit to generate the droplets, a dispenser to feed air pulses to the syringe unit, a gas-tight tank, a test metal foil on which the droplets impinge, observation equipment for flash photography, and a high-speed quantum-type infrared thermometer to measure the temperature of the test sheet.

The test liquid was stored in the syringe at room temperature. A droplet was formed at the nozzle exit, and it eventually detached because of gravity. The nozzle unit was equipped with a K-type thermocouple to measure the temperature of the nozzle. The falling droplets were directly captured by an optical sensor, which was used to create trigger signals for flash photography and record the measured foil temperature.

A rectangular stainless steel foil, with a length of $60 \mathrm{~mm}$, width of $10 \mathrm{~mm}$, and thickness of $0.1 \mathrm{~mm}$, was adopted as the test substrate. The rear surface of the test foil was thinly coated with black-body paint having an emissivity of 0.94 to enable the infrared thermometer to correctly measure the local solid temperature. The test foil was mounted on a heat-insulating base having a hole with a diameter of $10 \mathrm{~mm}$ for infrared thermometry. The foil was tightly stretched in the longitudinal direction to prevent undesirable local deformation due to local thermal stress caused by rapid cooling during droplet impacts. The test foil was heated by electric resistance heating, with direct current flowing through the sheet. In the present study, the initial temperature of the solid surface, $T_{w}$, was set in the range $140-470^{\circ} \mathrm{C}$.

The infrared thermometer, which was equipped with an indium-antimony device, was set $10 \mathrm{~cm}$ below the rear surface of the test foil. The thermometer could perform measurements in a 3.5-mm-diameter circular area with a temporal resolution of $1 \mathrm{~ms}$. The measurement uncertainty of the thermometer was $\leq 3.5{ }^{\circ} \mathrm{C}$ (specified by the manufacturer). The temperature data were recorded using a data logger with a sampling 
time of $0.1 \mathrm{~ms}$. A K-type thermocouple was also attached to the test foil to calibrate the infrared thermometer and maintain the temperature of the solid surface at a preset value using a temperature controller. The test foil, heat-insulating base, and infrared thermometer were mounted on a multi-axis transverse stage, which could adjust their positions with a resolution of $0.01 \mathrm{~mm}$.

A two-directional observation technique was utilized to observe the collision behavior of the droplets with the solid [22]. Two digital still cameras with an effective spatial resolution of $5184 \times 3456$ pixels and three strobe lights were used as shown in Fig. 3. Doubly exposed, backlit side-view images of the droplets were taken by aligning one of the cameras (camera A), the stainless steel foil, and a pair of strobe lights horizontally. The images were used to measure the impact conditions, including the pre-impact diameter of the droplets, the impact velocity, and the elapsed time after the impact of a droplet on the solid. The other camera (camera B) and its flash unit were arranged to provide bird's-eye-view images of the droplets. For each run, a pair of images was captured using cameras A and B simultaneously. To follow the time evolution of the shape of the droplets, impact tests were performed under the same experimental conditions for different flash timings. More information on the flash-photography technique is available in our previous work [22].

The time evolution of the temperature of the rear surface of the foil was measured 30 times or more for each impact condition. The time series of the measured temperatures were averaged as follows:

$$
T_{m}(t)=\frac{1}{N} \sum_{n=1}^{N} T_{n}(t), \quad \sigma=\sqrt{\frac{1}{N} \sum_{n=1}^{N}\left(T_{n}(t)-T_{m}(t)\right)^{2}}
$$

where $T_{m}, T_{n}, t$, and $N$ represent the averaged temperature, measured temperature, time, and number of runs, respectively. The error range $\sigma$ was calculated using the standard deviation of the average value. 
After runs in which the substrate temperature was low, some oil remained on the solid surface. To remove the residual oil and keep the substrate surface clean, the solid surface was wiped carefully with ethanol after each run.

\subsection{Test liquid}

The test emulsion was prepared by stirring a mixture of base oil and water in a mixing machine for $20 \mathrm{~min}$ at $6500 \mathrm{rpm}$. The composition of the base oil was $95.0 \mathrm{wt} \%$ mineral oil and $5.0 \mathrm{wt} \%$ emulsifier. Both the base oil and the emulsifier are commonly used in actual cold rolling processes applied to metal sheets. O/W emulsions with three oil concentrations (1, 5, and $15 \mathrm{wt} \%)$ were used as the test liquids; the tested concentrations were selected based on actual metal-forming conditions, including standard metal sheet-rolling processes as well as processes that require greater oil adhesion to the metal surface for lubrication purposes. The mean diameters of the dispersed oil droplets in the emulsion were approximately 8-9 $\mu \mathrm{m}$, as measured by the Coulter counter method (aka., electrical sensing zone method). Each experiment was performed within a few hours of preparing the $\mathrm{O} / \mathrm{W}$ emulsion so that the oil droplets in the emulsion remained in a metastable dispersed state and the mean diameter of the oil droplets remained almost unchanged during the experiment.

The collision behaviors of both water and base oil droplets were also tested for reference. The measured thermophysical properties of water, the test emulsion, and the base oil at $20{ }^{\circ} \mathrm{C}$ are listed in Table 1 . The surface tension of the emulsion is smaller than that of water even for small oil concentrations because of the presence of a surfactant (emulsifier). The surfactant reduces the surface tension between the oil and aqueous phases to stabilize the dispersed state, as shown in Fig. 1. The surfactant also exists at the air-liquid interface, which reduces the surface tension of the emulsion. The 
base oil has high viscosity, low specific heat, and low thermal conductivity compared to water. Therefore, the thermophysical properties of the emulsion are dependent on the oil concentration.

The contact angle of the test fluid with the test solid is also an important factor governing the wettability of the liquid on the solid surface. The contact angle was measured at room temperature as follows. Droplets were very gently placed on the foil surface, which was chemically cleaned in advance of the measurement, and the droplets eventually deformed into a dome-shaped mass. The dome-shaped droplets were photographed by camera $\mathrm{A}$, and the contact angle was directly measured from the images. The contact angles were approximately $70^{\circ}$ for water and for the $1 \mathrm{wt} \%, 5 \mathrm{wt} \%$, and $15 \mathrm{wt} \%$ emulsions. For the base oil, the contact angle was approximately $30^{\circ}$, indicating that the base oil had considerably better wettability on the test foil than water and the test emulsions.

In the experiments, the droplet size was slightly varied depending on the type of the test liquid. The pre-impact diameter of the droplets, $d_{P}$, was approximately $2.6 \mathrm{~mm}$ for water, approximately $2.5 \mathrm{~mm}$ for the $1 \mathrm{wt} \%$ and $5 \mathrm{wt} \%$ emulsions, approximately 2.4 $\mathrm{mm}$ for the $15 \mathrm{wt} \%$ emulsion, and approximately $2.2 \mathrm{~mm}$ for the base oil. The impact velocity of the droplets, $v$, was fixed to $1.0 \mathrm{~m} / \mathrm{s}$ for all liquid types by adjusting the nozzle-to-foil spacing.

\section{Results and discussion}

3.1 Hydrodynamics and heat transfer characteristics of water and 1-wt\% emulsion droplets at various initial foil temperatures 
Fig. 4 presents a sequence of photographs showing the collision of water and the 1-wt\% emulsion droplets with a hot solid for various foil temperatures. The images were taken by camera B, as shown in Fig. 3. In each photograph, the elapsed time after the droplet impact on the solid was represented. Namely, the moment of droplet impact on the solid was set to $t=0 \mathrm{~s}$. The deformation behavior of the droplets is strongly dependent on the initial solid temperature. At $T_{w}=140{ }^{\circ} \mathrm{C}$, the droplets impact the solid surface, spread radially, and reach their maximum extension. Thereafter, the wet area decreases with time, and then, the liquid in the center region swells. Very weak boiling is observed for both the liquids. The liquid shape is almost axisymmetric during the entire deformation process. With an increase in the initial solid temperature (140$290{ }^{\circ} \mathrm{C}$ ), the boiling vapor bubbles increase in number and size. The liquid shape is roughly axisymmetric at $T_{w}=230$ and $290{ }^{\circ} \mathrm{C}$. At $T_{w}=380{ }^{\circ} \mathrm{C}$, strong nucleate boiling occurs. The boiling vapor bubbles at the liquid-atmosphere interfaces burst, which causes numerous minute droplets to be formed, and the free surface becomes very lumpy. At $T_{w}=470{ }^{\circ} \mathrm{C}$, the number of minute droplets formed is less than that at $380{ }^{\circ} \mathrm{C}$. In all the cases, the deformation behaviors of the water and the 1-wt $\%$ emulsion are moderately similar to each other.

Fig. 5 shows the time evolutions of the measured temperatures on the rear surface of the stainless steel foil at several solid temperatures for five types of liquids. The error bars in the figure show the standard deviation of the average value, as defined in Eq. (1). The measured foil temperatures are equal to the preset initial temperatures before the moment of droplet impact. When the droplet impacts the substrate, the foil temperature in the impact region reduces. This reduction is reflected on the rear surface with a certain time delay because of heat conduction inside the solid. Consequently, the measured temperatures begin to decrease not at the moment of droplet impact, but at $t \sim$ 1 ms. The measured temperatures decrease monotonically with time. 
This subsection focuses on the results for water and the 1-wt\% emulsion, and the temperature histories for the other test liquids are discussed in a later subsection. In terms of physical properties (Table 1), the surface tensions of water and the 1-wt\% emulsion are significantly different. Before the experiments were performed, we believed that the difference in the surface tensions could potentially have an appreciable influence on the boiling phenomena, particularly in the nucleate boiling regime [23-26]. However, the effect of varying the surface tension on the hydrodynamics of the droplets was found to be minor, as shown in Fig. 4. In addition, the temperature histories of water and the 1-wt\% emulsion show similar trends (Fig. 5), although a slight difference can be seen at $T_{w}=170^{\circ} \mathrm{C}$. One possible reason for this difference is that the time scale considered for analyzing droplet deformation in the present experiments is small compared to the time required for growing sufficiently large vapor bubbles.

It is well known that water can conditionally exist in a metastable, superheated liquid state when it is heated above its boiling temperature but below the superheat temperature limit. The superheat limit of water is approximately $300{ }^{\circ} \mathrm{C}$ at atmospheric pressure $[27,28]$. Above this limit, a rapid phase change from water to vapor occurs. As shown in Fig. 5, the measured foil temperature for water is higher than $300{ }^{\circ} \mathrm{C}$ even at $t$ $=10 \mathrm{~ms}$ when $T_{w}=470{ }^{\circ} \mathrm{C}$. In contrast, the measured temperature decreases below the superheat limit during the collision with the droplets at $T_{w}=380{ }^{\circ} \mathrm{C}$. Although the measured solid temperature on the rear surface did not coincide with the liquid temperature, it is considered that liquid-solid direct contact occurs temporally as well as locally, at least, at later times when $T_{w}=380^{\circ} \mathrm{C}$.

It should be noted that a very thin stainless steel foil is adopted as the test solid in the present study. Unlike many prior studies that use a thick hot solid, the heat capacity of the solid used in the present study is quite small and no recovery of the solid temperature occurs because of heat conduction inside the solid. The deformation and 
heat transfer characteristics of droplets on a thin solid are probably different from those on a thick solid at later times because the temperature reduction in a thin solid is larger than that in a thick solid.

\subsection{Effects of varying oil concentration on hydrodynamic behavior of emulsion droplets and resultant temperature profiles of solid}

Fig. 6 shows the collision behavior of the 5- and 15-wt\% emulsion droplets with a solid under various initial foil temperatures. Both these emulsion liquids have very low degrees of transparency compared to the 1-wt\% emulsion and water because in the former emulsion liquids, numerous oil droplets scatter the observation light. The boiling phenomena inside the droplets cannot be analyzed for the 5- and 15-wt\% emulsions.

The results for the 5- and 15-wt\% emulsions (Fig. 6) are compared with those for the 1 -wt\% emulsion (Fig. 4) to investigate the effect of varying oil concentrations. The deformation behaviors of the droplets for the two emulsions show moderately similar trends in the temperature range $T_{w}=140-290{ }^{\circ} \mathrm{C}$. At $T_{w}=380{ }^{\circ} \mathrm{C}$, an appreciable difference is seen between the results for the $15-\mathrm{wt} \%$ emulsion and the other test liquids. For the 1- and 5-wt\% emulsions, boiling bubbles burst when the droplets deform into a disk. This results in the formation of numerous minute droplets. The main body of the liquid becomes distorted and lumpy. In contrast, the shape of the $15-w t \%$ emulsion droplets is maintained to be roughly axisymmetric in all the deformation stages. At $T_{w}=$ $470{ }^{\circ} \mathrm{C}$, some dry areas are formed because of the bursting of bubbles in the center region at 5.0 and $7.2 \mathrm{~ms}$ for the $1-\mathrm{wt} \%$ emulsion. No dry area is observed and an almost axisymmetric shape is maintained for the $15-w t \%$ emulsion.

Fig. 7 shows the collision behavior of the base oil droplets at various initial solid 
temperatures. Because the base oil is transparent, the boiling phenomena at the liquidsolid interface can be clearly seen. At $T_{w}=290{ }^{\circ} \mathrm{C}$, few boiling bubbles are seen inside the liquid because the boiling temperature of the base oil is approximately $300{ }^{\circ} \mathrm{C}$. Because the wettability of the base oil on the solid is better than that of water and the emulsions, the base oil droplet spreads more widely than the droplets of the other liquids. At $T_{w}=380{ }^{\circ} \mathrm{C}$, a small number of bubbles are seen. At $T_{w}=440{ }^{\circ} \mathrm{C}$, bubbles increase in number and size compared to the previous cases. Bursting of bubbles occurs to a small extent on the free surface. At $T_{w}=470{ }^{\circ} \mathrm{C}$, a vaporized oil film is formed between the liquid and solid. Overall, the boiling phenomena of the base oil are very mild compared to those of the emulsions and water.

The results for the base oil suggest that almost all instances of bursting bubbles (Figs. 4 and 6) can be attributed to vaporized water. Thus, the reason why a few minute droplets are observed for the 15 -wt\% emulsion could be explained by the following mechanism. When the droplet impacts the foil, some amount of water is soon vaporized in the region very close to the foil surface, followed by an increase in the local oil concentration, as illustrated in Fig. 8. Thus, the chance of water-solid direct contact decreases significantly. It is also considered that the boiling vapor bubbles cannot grow upward in the direction normal to the foil surface because of the high viscosity of the oil-rich layer and/or the presence of oil droplets. Consequently, the bursting of vapor bubbles rarely occurs. The droplets can be kept in the axisymmetric shape and the rebounding phenomena appear.

Next, we consider the results of Fig. 5 to study the effect of varying oil concentrations on the temperature histories of the foil. At $T_{w}=140$ and $170{ }^{\circ} \mathrm{C}$, the foil temperatures decrease monotonically with time. The temperature reduction is larger at smaller oil concentrations. Because no boiling or weak boiling of water occurs at these $T_{w}$ values, the effect of phase changes of liquids on the heat transfer characteristics is 
negligibly small. Thus, it is concluded that the results are attributable to the difference in thermal conductivity, as listed in Table 1. In addition, the temperatures for 5- and 15 -wt $\%$ emulsions are very similar. The obtained results indicate that, in both cases, the foil surface is not covered with liquid composed of water and dispersed oil droplets, but is instead covered mainly with an oil film because of the oil's favorable wettability.

At $T_{w}=230$ and $290{ }^{\circ} \mathrm{C}$, the foil temperature decreases to a larger extent for smaller oil concentrations because the nucleate boiling of water enhances the heat transfer. The temperature reduction for the base oil is very small because the thermal conductivity is small and no boiling occurs.

At $T_{w}=380{ }^{\circ} \mathrm{C}$, the temperature variations in the foil for the $15-\mathrm{wt} \%$ emulsion and base oil show very similar paths. This is probably because a local oil-rich layer is formed and a water phase is rarely present in the vicinity of the foil surface. The measured foil temperature is lower at smaller oil concentrations. Similar trends can be seen at $T_{w}=470{ }^{\circ} \mathrm{C}$.

\subsection{Heat transfer characteristics}

A lumped capacitance model is adopted to evaluate the transient heat transfer from the test foil to the droplets. The following simple relationship for energy conservation is considered, assuming that the heat removal on the wet surface is equal to the time variation of the internal heat energy in a cylindrical region as illustrated in Fig. 9:

$$
q A=\rho c \frac{d T_{m}}{d t}(A d)
$$

where $q, A, \rho, c$, and $d$ represent the heat flux on the wet surface, 3.5-mm-diameter measurement area of the thermometer, material density, specific heat, and thickness of the sheet $(0.1 \mathrm{~mm})$, respectively. Heat loss due to natural convection to the atmosphere 
from the surface is cancelled by the electric resistance heating during experiments; therefore, the heat generation term is omitted. In addition, the heat loss due to heat conduction in the direction parallel to the solid surface was neglected. The physical properties of the foil are assumed to be constant. The time derivative of temperature is calculated by a simple finite-difference approximation using the measurement data as follows:

$$
\frac{d T_{m}(t)}{d t} \approx \frac{T_{m}(t+\Delta t / 2)-T_{m}(t-\Delta t / 2)}{\Delta t}
$$

The time increment, $\Delta t$, is set to be $1 \mathrm{~ms}$, taking into account the temporal resolution of the thermometer. Heat flux can be calculated by

$$
q(t) \approx \rho c d \frac{T_{m}(t+\Delta t / 2)-T_{m}(t-\Delta t / 2)}{\Delta t} .
$$

Fig. 10 shows the time evolution of the heat flux (evaluated using Eq. (4)) for the 1-wt\% emulsion. In all the cases, the heat flux increases sharply with time, reaches a maximum value, and then decreases. Large heat removal is achieved only in a short period after the droplet impact. The peak heat flux increases with an increase in the solid temperature when $T_{w} \leq 380{ }^{\circ} \mathrm{C}$. In contrast, the heat flux decreases with an increase in $T_{w}$ when $T_{w} \geq 380{ }^{\circ} \mathrm{C}$. In addition, the peak values show larger time delays at larger $T_{w}$ values.

Before we discuss the results in detail, the range of applicability of the present lumped capacitance model is investigated in terms of the Biot number and the spatial resolution of the thermometer. The Biot number, which is a dimensionless parameter defined by the ratio of the heat transfer resistance inside the solid to that on the solid surface, should be considerably smaller than unity for evaluating heat flux with small errors [29]. In the present case, the maximum value of the Biot number is approximately 0.4 at $t \sim 3 \mathrm{~ms}$ when $T_{w}=380{ }^{\circ} \mathrm{C}$, indicating that the results contain some error. 
The measurement area of the thermometer has a diameter of $3.5 \mathrm{~mm}$, which is larger than the pre-impact diameter of the droplets. Photographic observation reveals that the apparent liquid-solid contact diameter is smaller than the diameter of the measurement area of the thermometer before $t \sim 0.8 \mathrm{~ms}$. In addition, the time derivation of the temperature in Eq. (4) is approximated by using the measured temperature on the rear surface alone. These facts induce some error in the predictions at early times. When $T_{w} \leq 320{ }^{\circ} \mathrm{C}$, the peak heat fluxes appear at almost the same time ( $t \sim 2 \mathrm{~ms}$ ). It is considered that the time at which the peak appears depends on the solid temperature. Thus, the results are probably incorrect because of the poor time resolution of the present model.

Here, we focus on the results for $T_{w} \geq 380{ }^{\circ} \mathrm{C}$. In these cases, the heat flux increases with time and reaches a peak value when $t>3 \mathrm{~ms}$. The peak heat fluxes are smaller for higher initial foil temperatures because more vapor is generated and liquidsolid direct contact occurs less often. Thereafter, the heat flux decreases monotonically with time because most of the liquid is located away from the solid surface. For the 1-wt\% emulsion (Fig. 4(f)), local breakage of the liquid film occurs in the center region and dry areas appear at 5.0 and $7.2 \mathrm{~ms}$. The local breakage of the liquid film occurs later at higher temperatures, and consequently, the peak heat flux shows larger time delays.

Makino and Michiyoshi [12] conducted experiments on 2.54-4.50-mm-diameter water droplets placed on hot metal surfaces (copper, brass, carbon steel, and stainless steel). Wet surface temperatures were measured with a thermocouple. These researchers reported that the largest value of time-averaged heat flux during droplet contact on the substrate was approximately $10^{7} \mathrm{~W} / \mathrm{m}^{2}$ or more. Chen and Hsu [13] studied the collision of water droplets with diameters of 2.8-4.8 mm with a hot Inconel 600 alloy substrate equipped with a microthermal probe for measuring the temperature of the wet surface. The impact velocity was 0.5 to $2.0 \mathrm{~m} / \mathrm{s}$. These researchers reported that the average heat 
flux during contact is strongly affected by the initial temperature of the solid, and the impact velocity is of secondary importance. In their work, the average heat flux is around $10^{7} \mathrm{~W} / \mathrm{m}^{2}$ when the temperature of the substrate is larger than $350{ }^{\circ} \mathrm{C}$.

The heat flux distribution for water shows similar trends to the result for the $1-w t \%$ emulsion, although these results are not shown. We define the time-averaged heat flux as follows:

$$
\bar{q}=\frac{1}{t} \int_{0}^{t} q d t
$$

In the case of $T_{w}=380{ }^{\circ} \mathrm{C}$ and $\mathrm{t}=10 \mathrm{~ms}, \bar{q}=8.8 \times 10^{6} \mathrm{~W} / \mathrm{m}^{2}$ is obtained. This value agrees moderately with the data reported in [12] and [13].

The heat flux is a useful index for discussing the heat transfer characteristics, but it contains some inevitable errors, as previously described. Therefore, we introduce another parameter: the temperature decrease from the initial foil temperature to the measured temperature, $\Delta T$, at a certain end time. In the present study, $t=10 \mathrm{~ms}$ is chosen as the end time, where the heat flux is sufficiently small, as shown in Fig. 10. The parameter is a simple index to show the degrees of temperature reduction.

Fig. 11 shows the $\Delta T$ results for five types of test liquids and various foil temperatures. For water, $\Delta T$ increases almost linearly with the initial foil temperature, reaches a peak at $380{ }^{\circ} \mathrm{C}$, and then decreases linearly. For the base oil, $\Delta T$ is significantly smaller than that for water. In addition, the peak appears at $440{ }^{\circ} \mathrm{C}$. These differences in the results are obtained because of lower thermal conductivity, higher boiling temperature, and considerably milder boiling phenomena. The temperature decreases for the 1-wt\% emulsion show almost the same trends as those for water. The results for the 5 -wt\% emulsion show similar trends to those for the 1 -wt $\%$ emulsion, although $\Delta T$ is apparently smaller. This result suggests that an increase in the oil concentration inhibits the heat transfer. 
For the $15-w t \%$ emulsion, $\Delta T$ shows very different trends from those for the other test liquids. When $T_{w} \leq 230{ }^{\circ} \mathrm{C}, \Delta T$ is slightly smaller than that for the 5 -wt\% emulsion. At $T_{w}=320^{\circ} \mathrm{C}, \Delta T$ reaches a peak, which is considerably smaller than that for the 5 -wt $\%$ emulsion and larger than that for the base oil. In the range $T_{w}=320-$ $410{ }^{\circ} \mathrm{C}, \Delta T$ decreases with an increase in $T_{w}$, which indicates that the chance of water-foil contact decreases. In the range $T_{w}=410-470{ }^{\circ} \mathrm{C}, \Delta T$ shows an almost constant value and is smaller than that for the base oil. The reason for this result can be explained by the following mechanism. As shown in Fig. 6(f), the 15-wt\% emulsion droplet impacts the foil, spreads, recoils, and eventually rebounds off the foil at $T_{w}=$ $470{ }^{\circ} \mathrm{C}$. The apparent liquid-solid contact area is small at later times, suggesting that most of the liquid does not cool the foil. Similar trends are observed at 410 and $440{ }^{\circ} \mathrm{C}$, although they are not shown in this paper. In contrast, the base oil droplet spreads widely on the foil surface and cools it gently. Hence, $\Delta T$ for the base oil is slightly larger than that for the $15-\mathrm{wt} \%$ emulsion at $410-470{ }^{\circ} \mathrm{C}$.

The results shown in Fig. 11 provide some useful information from an engineering viewpoint. When an $\mathrm{O} / \mathrm{W}$ emulsion is used as a coolant, the water phase plays the role of a heat remover from the hot solid. The oil phase inhibits the heat transfer, particularly at high solid temperatures. The oil concentration in the emulsion should be a few weight percentages for achieving a high heat removal rate.

Finally, the present experimental results are validated by comparing the data with that of other researchers. Qiao and Chandra [14] studied the hydrodynamics and heat transfer characteristics of water and n-heptane droplets on a hot stainless steel surface in low and normal gravity. In their experiments, the temperature of the wet solid surface was measured using a thermocouple with a 10 - $\mu$ s response time. The maximum temperature decreases during droplet impact were reported based on the following conditions: that 2.0-mm-diameter water droplets impact the solid at an impact velocity 
of $0.8 \mathrm{~m} / \mathrm{s}$ under normal gravity. To validate the present $\Delta T$, the present data are compared to the maximum temperature decreases in the experiments of the previous researchers, although the points of temperature measurement and the experimental conditions are slightly different. Fig. 12 presents the comparison of the data of Qiao and Chandra with the $\Delta T$ of water in the present study for various initial temperatures of the solid. The two results are in good agreement with each other, indicating that the present results are consistent with the data of Qiao and Chandra.

\section{Conclusions}

In the present study, the hydrodynamics and heat transfer characteristics of emulsion droplets impinging on a hot solid were studied experimentally. The results obtained in the present study are summarized as follows:

(1) The effects of varying the solid temperature on the hydrodynamics and heat transfer characteristics of water droplets and 1-wt\% O/W emulsion droplets have been investigated. The results for the two liquids show similar trends, although the surface tension of water is considerably larger than that of the emulsion.

(2) The oil concentration has an appreciable influence on the deformation behavior of droplets at high foil temperatures because the boiling phenomena of the oil are considerably milder than that of water under the present experimental conditions. Bursting of vapor bubbles is observed for water and emulsions with low oil concentrations, resulting in the formation of minute droplets. Few minute droplets appear for the $15-w t \%$ emulsion and base oil.

(3) The heat transfer characteristics are strongly dependent not only on the solid temperature but also on the oil concentration. The water phase in the emulsion plays the role of cooling the hot solid, whereas the oil phase inhibits the heat transfer because of low thermal conductivity. In the case of the 15 -wt\% emulsion, a high oil 
concentration layer is probably formed on a solid surface that is heated to high temperatures. This results in considerable reduction in heat removal.

Funding: This work was supported the Japan Society for the Promotion of Science through a Grant-in-Aid for Scientific Research (c) [grant number 15K05825].

\section{Acknowledgement}

The authors would like to thank Mr. Takahiko Okamoto of Daido Chemical Industry for the fruitful discussion and great support with preparing test emulsions.

\section{References}

[1] E. Brinksmeier, D. Meyer, A.G. Huesmann-Cordes, C. Herrmann, Metalworking fluids-Mechanisms and performance, CIRP Annuals-Manufacturing Tech., 64(2015) 605-628.

[2] A. Cambiella, J.M. Benito, C. Pazos, J. Coca, M. Ratoi, H.A. Spikes, The effect of emulsifier concentration on the lubricating properties of oil-in-water emulsions, Tribol. Lett. 22 (2006) 53-65.

[3] W. Wang, P. Liu, G. Yao, Study on lubrication properties of emulsion for aluminum cold-rolling, Adv. Mater. Res. 228-229 (2011) 321-326.

[4] Y. Kimura, N. Fujita, Y. Mihara, Plate-out behaviors of O/W emulsions for cold rolling in a short time interval, Tetsu-to-Hagane 95 (2009) 20-26.

[5] A. Shirizly, J.G. Lenard, The effect of scaling and emulsion delivery on heat transfer during the hot rolling of steel strips, J. Mater. Process. Technol. 101 (2000) 250-259.

[6] M. Rein, Phenomena of liquid drop impact on solid and liquid surfaces, Fluid Dyn. Res. 12 (1993) 61-93. 
[7] M. Rein, Interactions between drops and hot surfaces, in: M. Rein (Ed.), Drop-Surface Interactions, Springer-Verlag Wien, New York, 2002, pp. 185-217.

[8] A.L. Yarin, Drop impact dynamics: Splashing, spreading, receding, bouncing..., Ann. Rev. Fluid Mech. 38 (2006) 159-192.

[9] S.T. Thoroddsen, T.G. Etoh, K. Takehara, High-speed imaging of drops and bubbles, Ann. Rev. Fluid Mech. 40 (2008) 257-285.

[10] D. Quere, Leidenfrost dynamics, Ann. Rev. Fluid Mech. 45 (2013) 197-215.

[11] G. Liang, I. Mudawar, Review of drop impact on heated walls, Int. J. Heat Mass Transfer, 106 (2017),103-126.

[12] K. Makino, I. Michiyoshi, The behavior of a water droplet on heated surfaces, Int. J. Heat Mass Transfer, 27 (1984), 781-791.

[13] J.C. Chen, K.K. Hsu, Heat transfer during liquid contact on superheated surfaces, J. Heat Transfer 117 (1995) 693-697.

[14] Y. M. Qiao, S. Chandra, Boiling of droplets on a hot surface in low gravity, Int. J. Heat Mass Transfer, 39 (1996), 1379-1393.

[15] D. Chatzikyriakou, S.P. Walker, C.P. Hale, G.F. Hewitt, The measurement of heat transfer from hot surfaces to non-wetting droplets, Int. J. Heat Mass Transfer 54 (2011) $1432-1440$.

[16] J. Park, C. Min, S. Granick, D. Cahill, Residence time and heat transfer when water droplets hit a scalding surface, J. Heat Transfer 134 (2012) \#101503.

[17] K. Kimoto, Y. Owashi, Y. Omae, The vaporizing behavior of the oil droplet of water-in-oil emulsions on the hot surface, Bull. JSME 29 (1986) 4247-4255.

[18] C.T. Avedisian, M. Fatehi, An experimental study of the Leidenfrost evaporation characteristics of emulsified liquid droplets, Int. J. Heat Mass Transf. 31 (1988) 15871603.

[19] B. Prunet-Foch, F. Legay, M. Vignes-Adler and C. Delmotte, Impacting emulsion drop on a steel plate: influence of the solid substrate, J. Colloid Interface Sci., 199 
(1998), 151-168.

[20] T. Takashima, H. Shiota, Evaporation of an oil-in-water type emulsion droplet on a hot surface, Heat Transf.—Asian Res. 34 (2005) 527-537.

[21] N. Nagai, T. Matsumura, S. Yamaguchi, Y. Maeda, K. Ikebata, Liquid-solid contact at evaporation of water liquid droplet emulsified with lubricant and its adhesion situation, $14^{\text {th }}$ International Heat Transfer Conference, Washington D.C., ASME, IHTC14-22597 (2010) 815-821.

[22] H. Fujimoto, Y. Oku, T. Ogihara, H. Takuda, Hydrodynamics and boiling phenomena of water droplets impinging on hot solid, Int. J. Multiph. Flow 36 (2010) 620-642.

[23] G. Hetsroni, J.L. Zakin, Z. Lin, A. Mosyak, E.A. Pancallo, R. Rozenblit, The effect of surfactants on bubble growth, wall thermal patterns and heat transfer in pool boiling, Int. J. Heat Mass Transf. 44 (2001) 485-497.

[24] L. Judy, K. Sandra, A. Muthupandian, Effect of surfactants on the rate of growth of an air bubble by rectified diffusion, J. Phys. Chem. B, 109 (2005) 14595-14598.

[25] G. Hetsroni, M. Gurevich, A. Mosyak, R. Rozenblit, Z. Segal, Boiling enhancement with environmentally acceptable surfactants, Int. J. Heat Fluid Flow 25 (2004) 841-848.

[26] Y.M. Qiao, S. Chandra, Experiments on adding a surfactant to water drops boiling on a hot surface, Proc. R. Soc. Lond. A, 453 (1997) 673-689.

[27] C.T. Avedisian, The homogenous nucleation limits of liquids, J. Phys. Chem. Data 14 (1985) 695-729.

[28] J.H. Lienhard, Correlation for the limiting liquid superheat, Chem. Eng. Sci. 31 (1976) 847-849.

[29] F.P. Incropera, D.P. Dewitt, Fundamentals of Heat and Mass Transfer, fourth ed., John Wiley \& Sons, New York, 1996, p. 214. 


\section{List of Figure and Table captions}

Fig. 1: Schematic of oil-in-water $(\mathrm{O} / \mathrm{W})$ emulsion.

Fig. 2: Schematic diagram of experimental apparatus.

Fig. 3: Schematic diagram of photography setup.

Fig. 4: Deformation behaviors of water and $1 \mathrm{wt} \%$ emulsion drops at various substrate temperatures ( $T_{w}$ ): (a) $140{ }^{\circ} \mathrm{C}$, (b) $170{ }^{\circ} \mathrm{C}$, (c) $230{ }^{\circ} \mathrm{C}$, (d) $290{ }^{\circ} \mathrm{C}$, (e) $380{ }^{\circ} \mathrm{C}$, and (f) $470{ }^{\circ} \mathrm{C}$.

Fig. 5: Time histories of measured temperatures using five types of liquids for various solid temperatures ( $T_{w}$ ): (a) $140^{\circ} \mathrm{C}$, (b) $170{ }^{\circ} \mathrm{C}$, (c) $230{ }^{\circ} \mathrm{C}$, (d) $290{ }^{\circ} \mathrm{C}$, (e) $380{ }^{\circ} \mathrm{C}$, and (f) $470{ }^{\circ} \mathrm{C}$.

Fig. 6: Deformation behaviors of 5 and 15 wt $\%$ emulsion drops at various solid temperatures ( $T_{w}$ ): (a) $140^{\circ} \mathrm{C}$, (b) $170{ }^{\circ} \mathrm{C}$, (c) $230{ }^{\circ} \mathrm{C}$, (d) $290{ }^{\circ} \mathrm{C}$, (e) $380{ }^{\circ} \mathrm{C}$, and (f) $470^{\circ} \mathrm{C}$.

Fig. 7: Deformation behaviors of base oil drops at various solid temperatures $\left(T_{w}\right)$ : (a) $290{ }^{\circ} \mathrm{C}$, (b) $380^{\circ} \mathrm{C}$, (c) $440{ }^{\circ} \mathrm{C}$, and (d) $470{ }^{\circ} \mathrm{C}$.

Fig. 8: Schematic of highly oil-rich layer.

Fig. 9: Schematic of lumped capacitance model.

Fig. 10: Time evolution of heat flux based on lumped capacitance model for $1 \mathrm{wt} \%$ emulsion.

Fig. 11: Temperature decreases for various experimental conditions.

Fig. 12: Comparison of water temperature decreases with maximum temperature decreases reported by Qiao and Chandra [14].

Table 1: Physical properties of test liquid at $20^{\circ} \mathrm{C}$. 


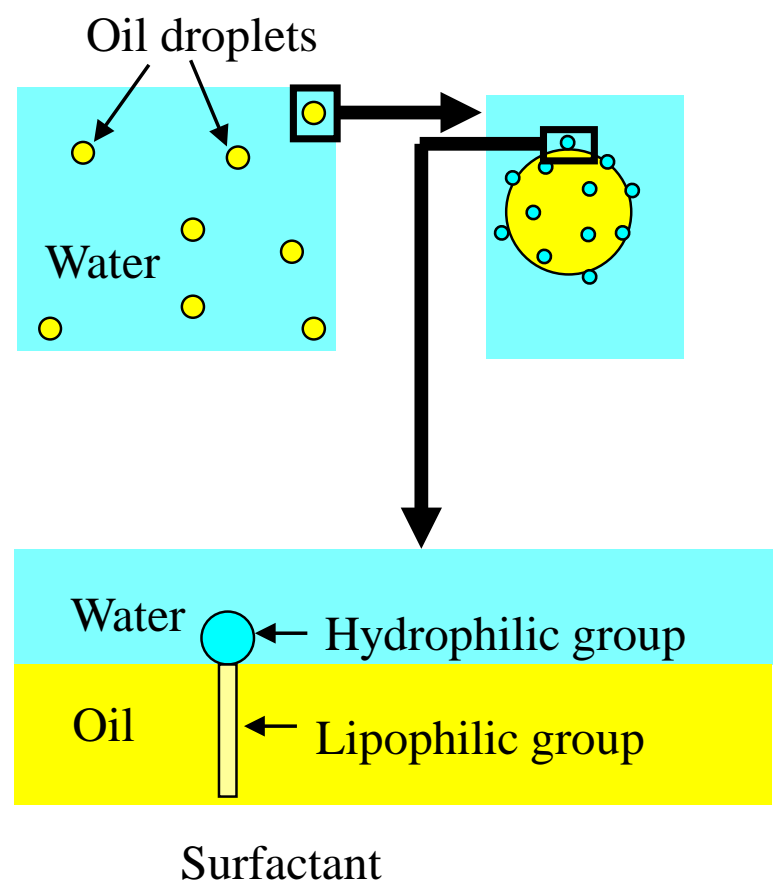

Fig. 1 Fujimoto et al. 



Thermocouple

Fig. 2 Fujimoto et al. 


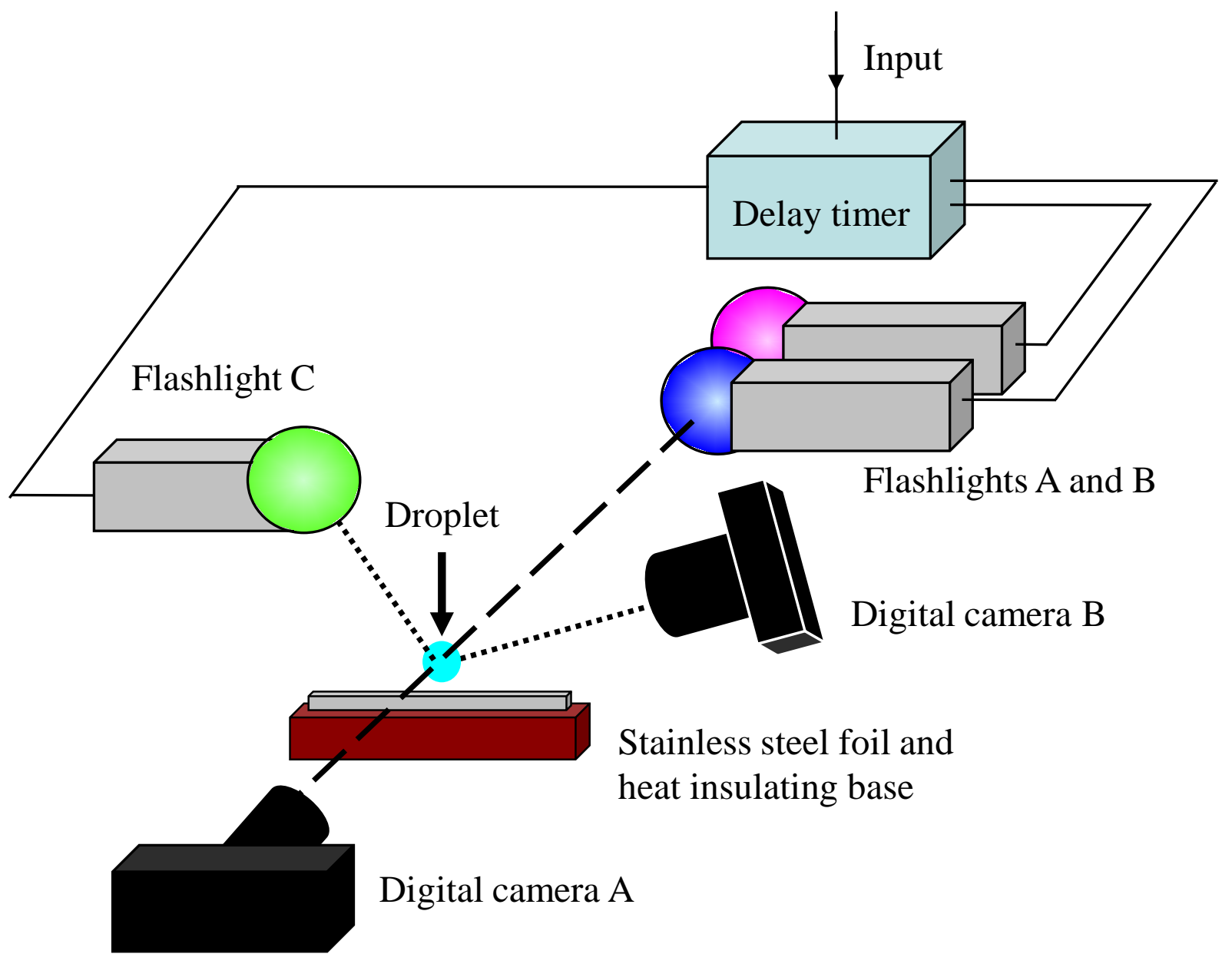

Fig. 3 Fujimoto et al. 

(a) $T_{w}=140{ }^{\circ} \mathrm{C}$

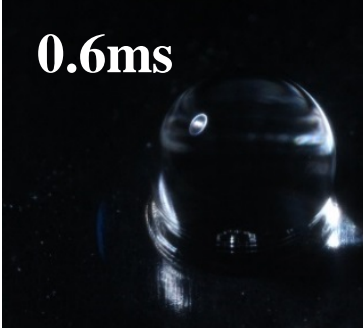

$2.6 \mathrm{~ms}$

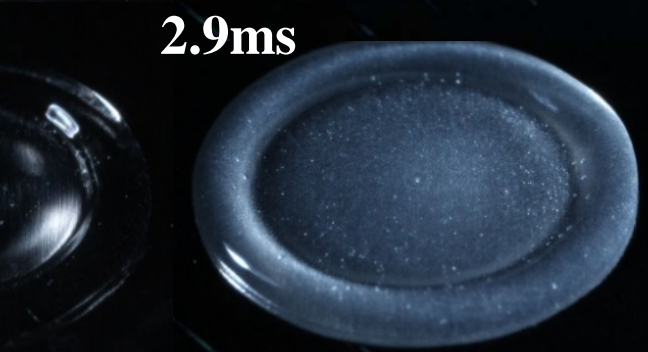

$4.6 \mathrm{~ms}$

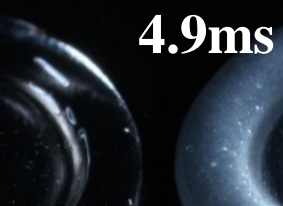



$6.5 \mathrm{~ms}$

$\checkmark$

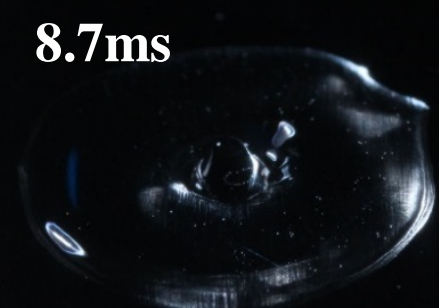

$10.5 \mathrm{~ms}$

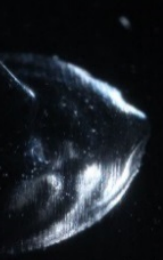

8.9ms

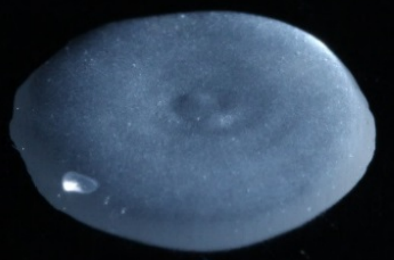

$10.9 \mathrm{~ms}$

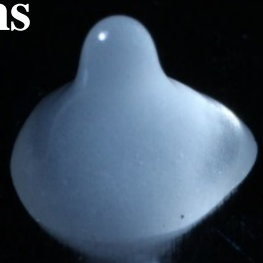

$5 \mathrm{~mm}$

water

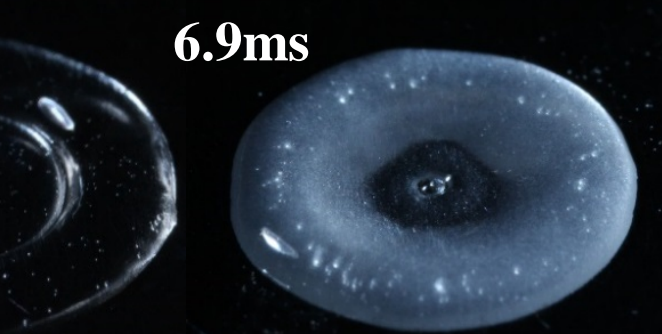

$6.5 \mathrm{~ms}$
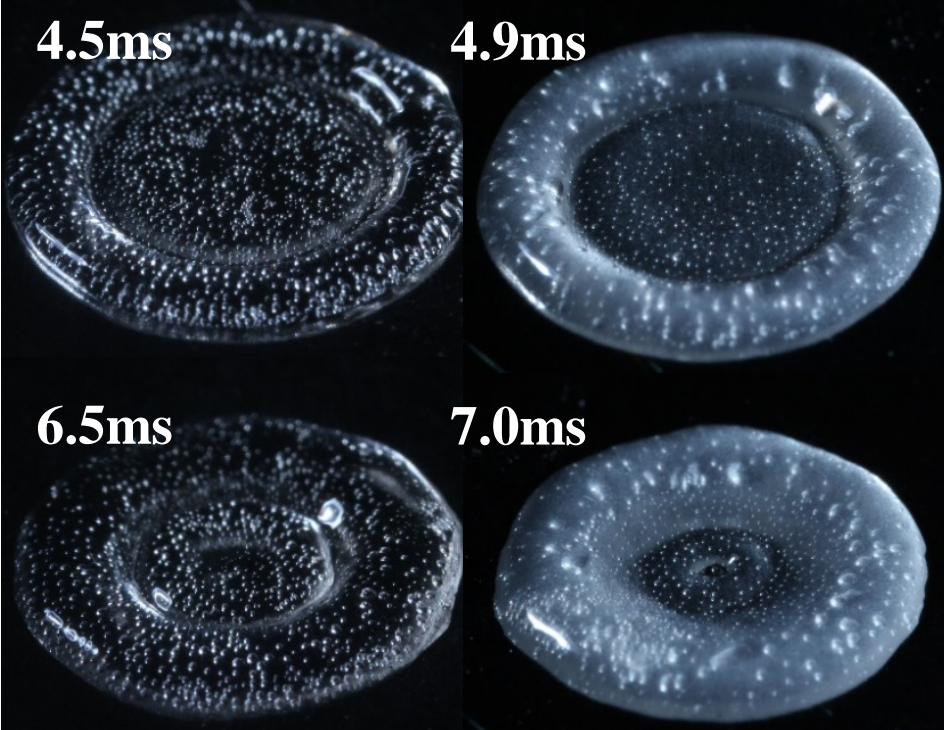

8.4ms

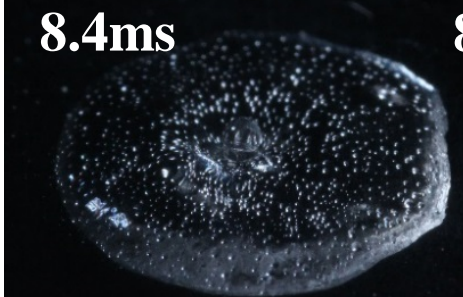

8.9ms
$10.4 \mathrm{~ms}$

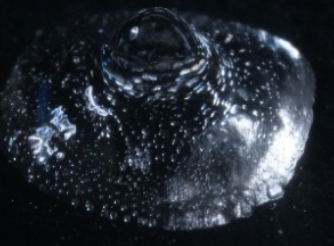

$0.9 \mathrm{~ms}$

$3.0 \mathrm{~ms}$

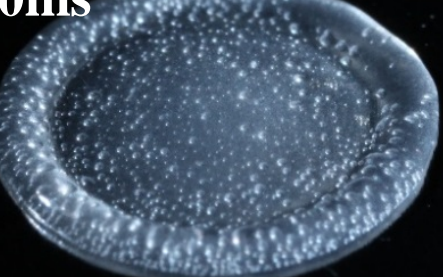

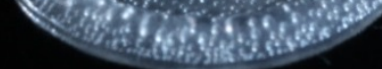

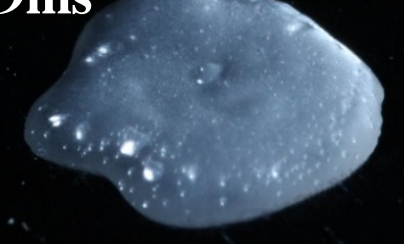

$11.0 \mathrm{~ms}$

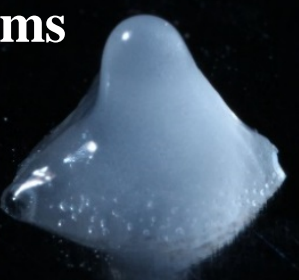

$5 \mathrm{~mm}$

water

$1 \mathrm{wt} \%$ emulsion

Fig. 4(a),(b) Fujimoto et al. 

(c) $T_{w}=230{ }^{\circ} \mathrm{C}$
(d) $T_{w}=290{ }^{\circ} \mathrm{C}$
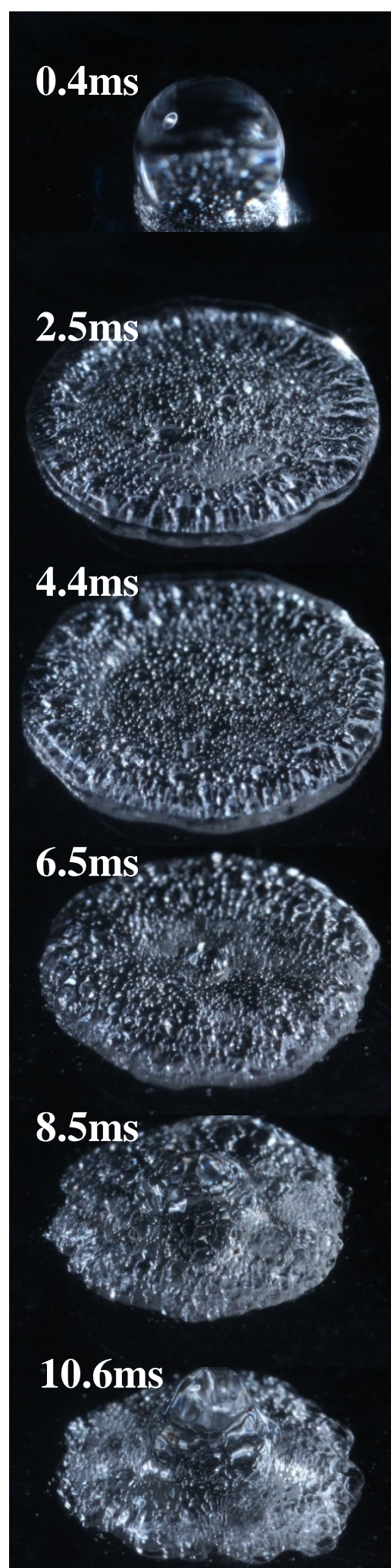
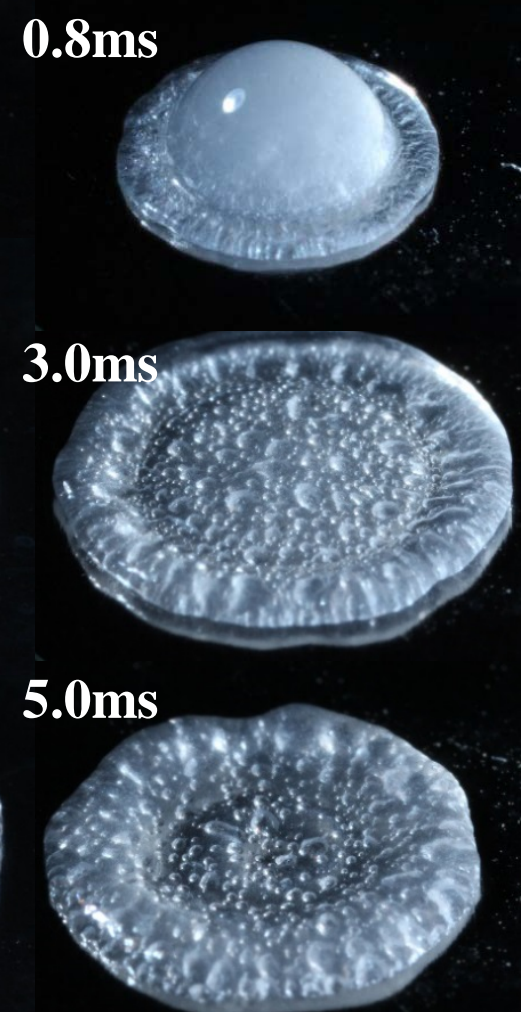

7.0ms
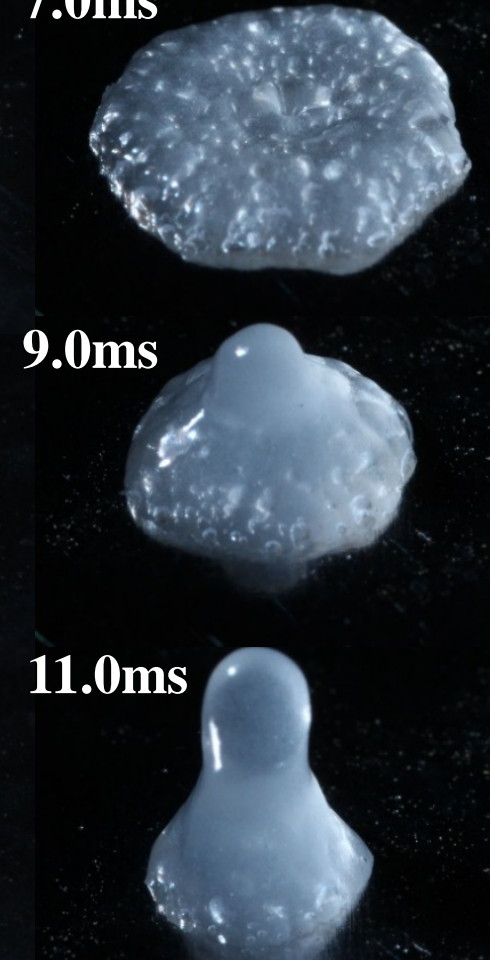




\section{$3.1 \mathrm{~ms}$}
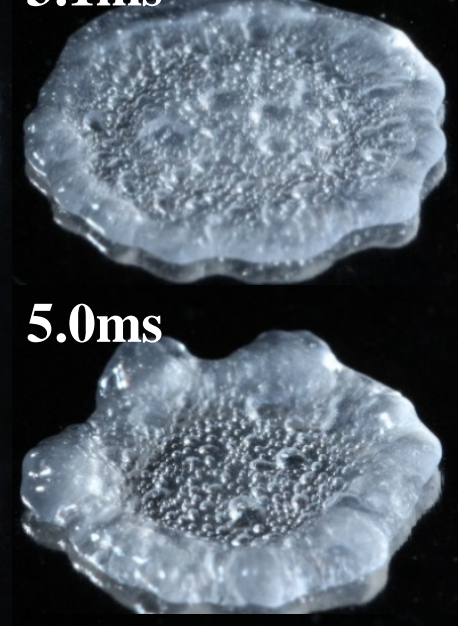

$7.0 \mathrm{~ms}$

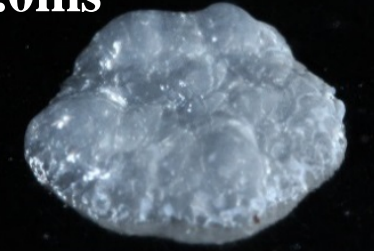

$9.0 \mathrm{~ms}$

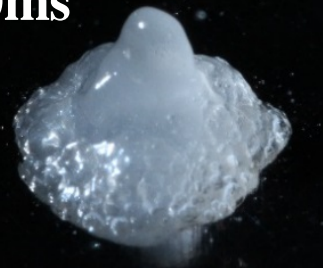

11.1ms

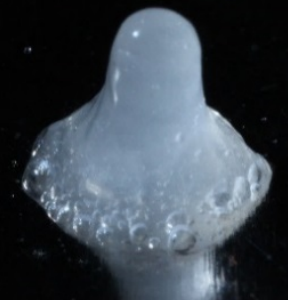

$5 \mathrm{~mm}$

water

$1 \mathrm{wt} \%$ emulsion

\section{$5 \mathrm{~mm}$}

water 

(e) $T_{w}=380{ }^{\circ} \mathrm{C}$

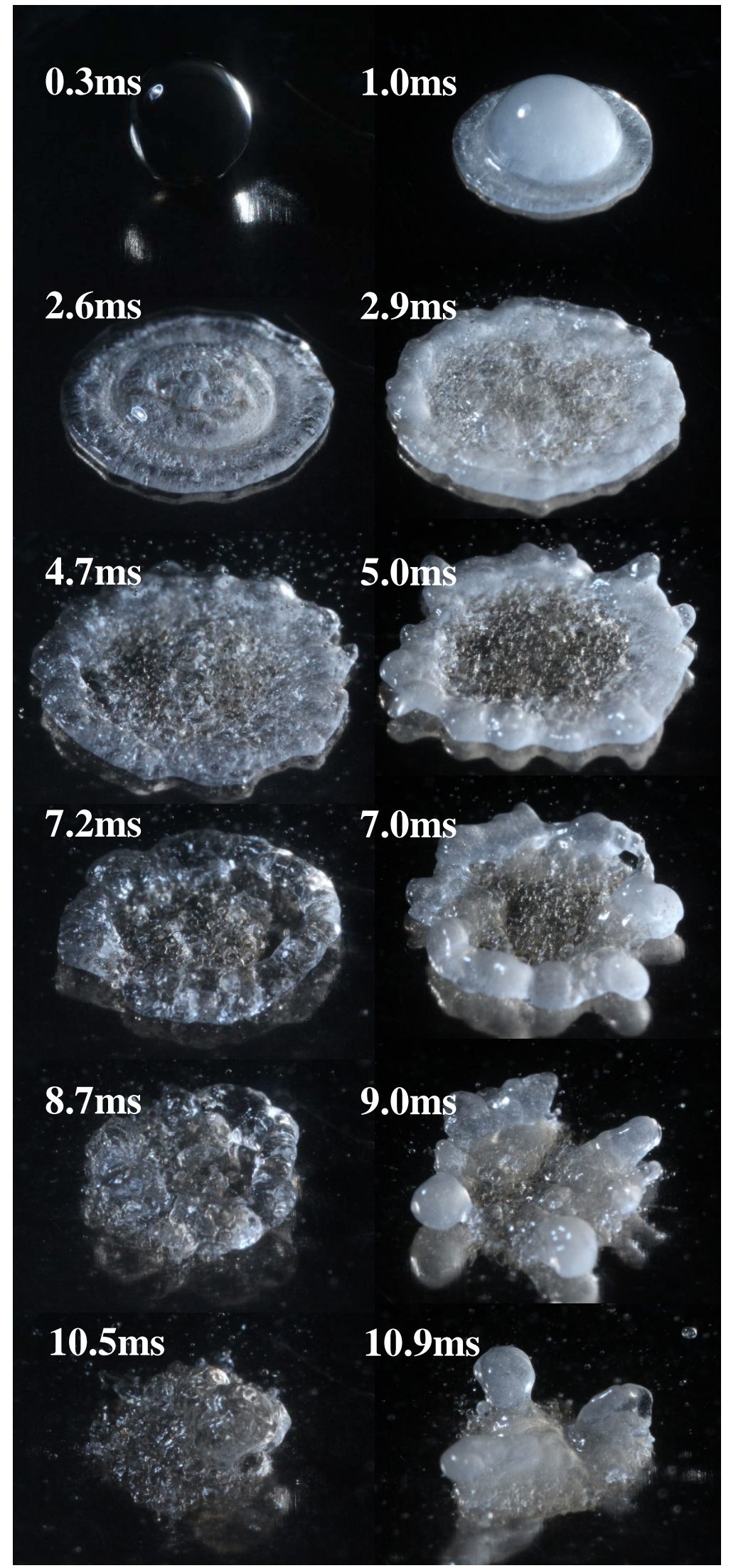

$5 \mathrm{~mm}$

water

(f) $T_{w}=470{ }^{\circ} \mathrm{C}$

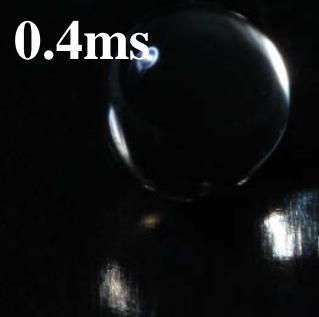

2.6ms
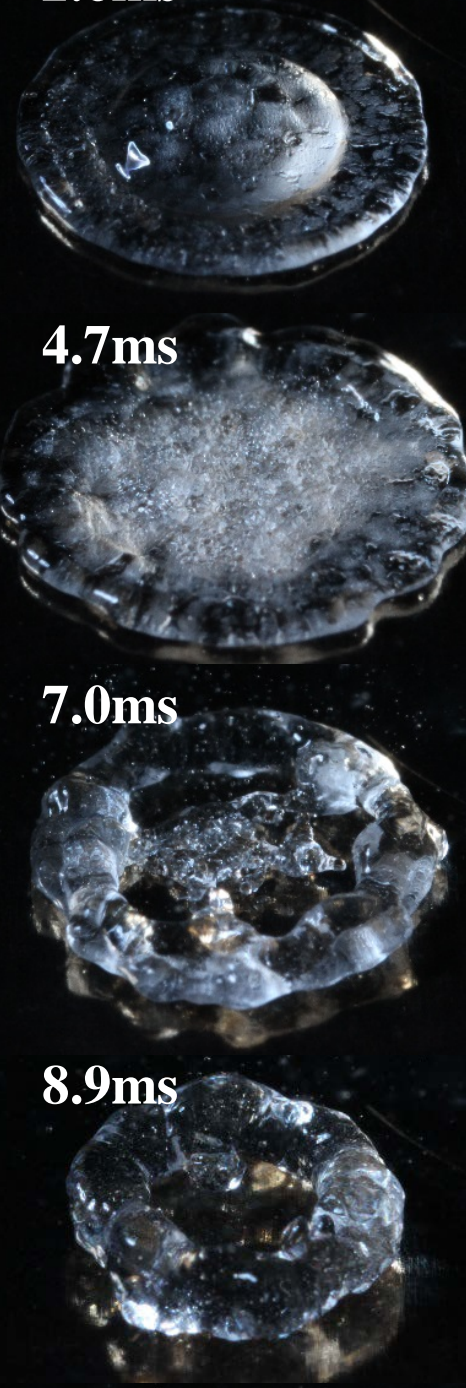

$10.8 \mathrm{~ms}$,

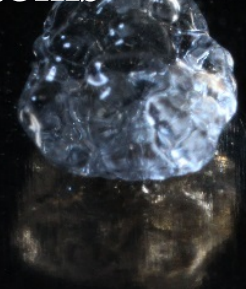

$0.9 \mathrm{~ms}$

$3.1 \mathrm{~ms}$

$5.0 \mathrm{~ms}$

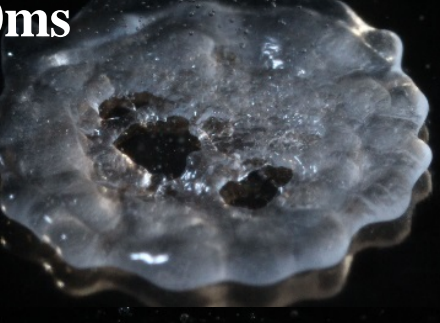

$7.2 \mathrm{~ms}$

$9.1 \mathrm{~ms}$

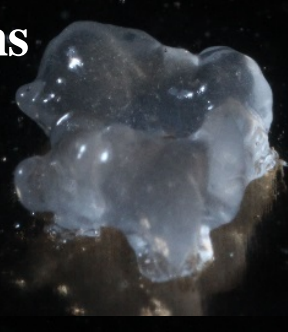

$11.2 \mathrm{~ms}$

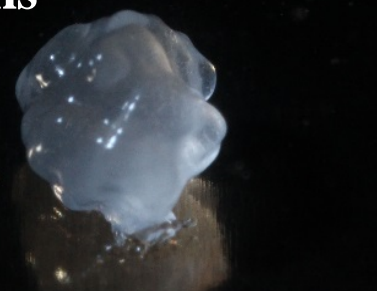

$5 \mathrm{~mm}$

water $1 \mathrm{wt} \%$ emulsion

Fig. 4(e),(f) Fujimoto et al. 

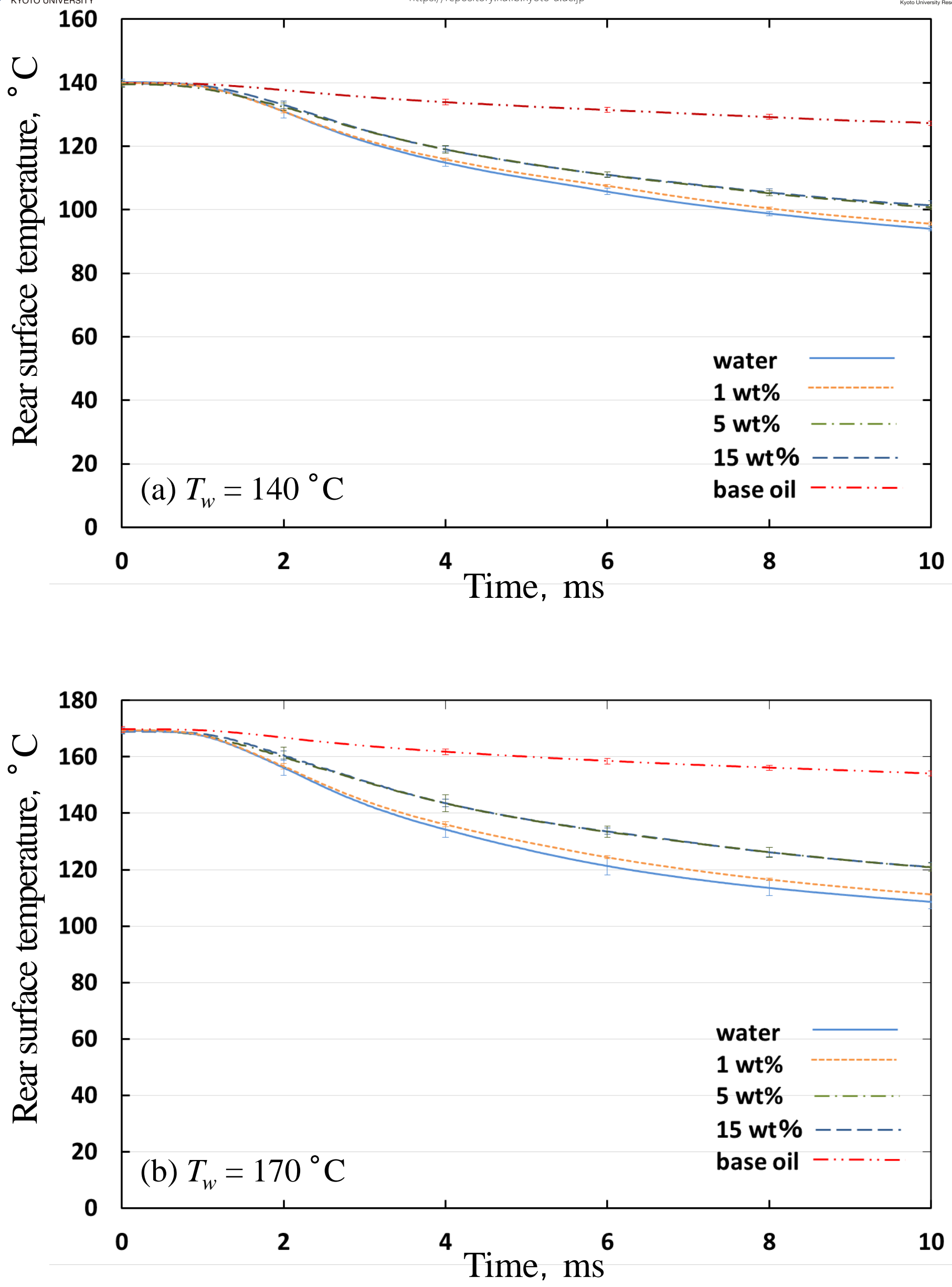

Fig.5(a),(b) Fujimoto et al. 

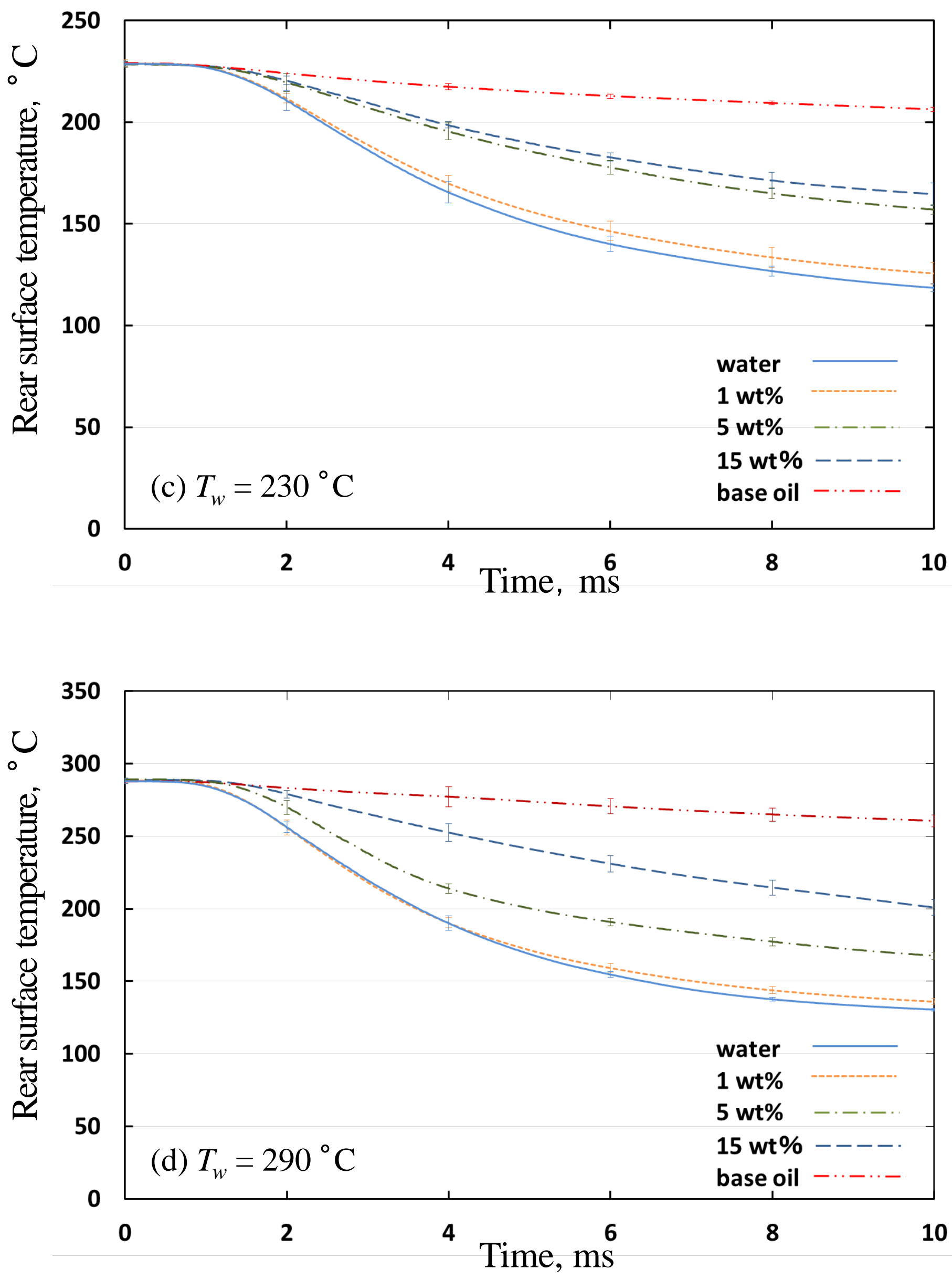

Fig.5(c),(d) Fujimoto et al. 

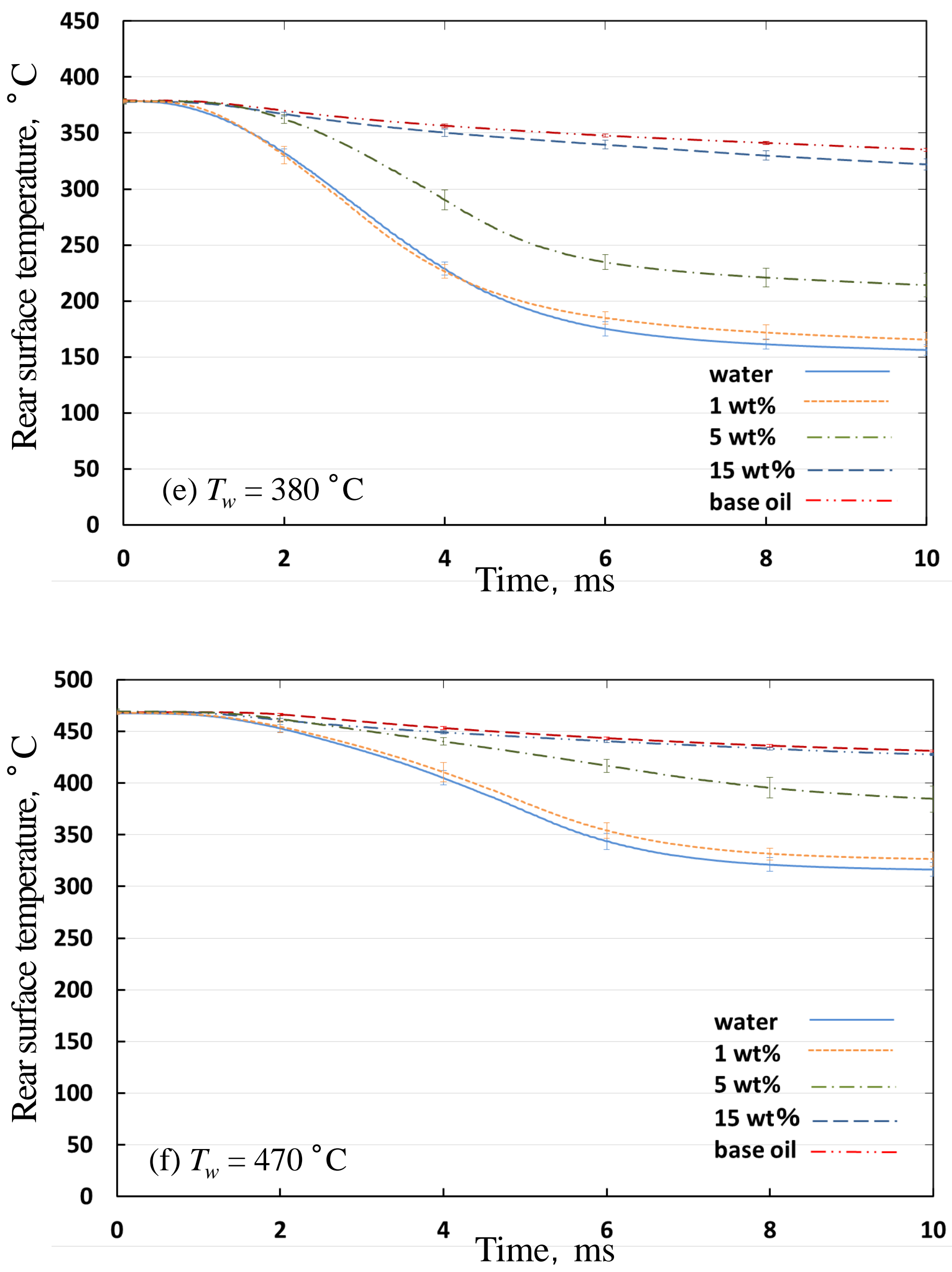

Fig.5(e),(f) Fujimoto et al. 

(a) $T_{w}=140{ }^{\circ} \mathrm{C}$

\section{$1.2 \mathrm{~ms}$}

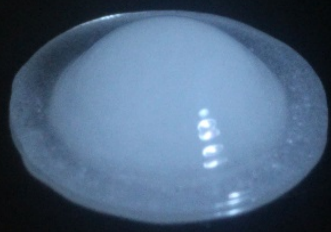

\section{$3.2 \mathrm{~ms}$}

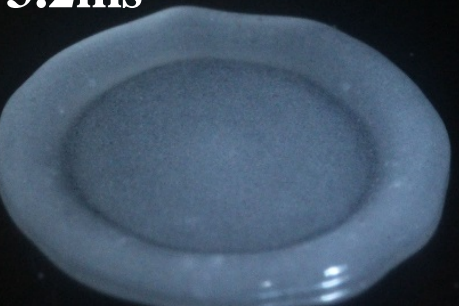

$5.1 \mathrm{~ms}$



7.1ms

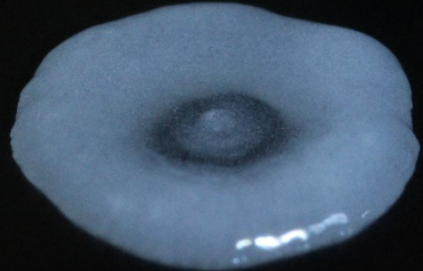

8.5ms

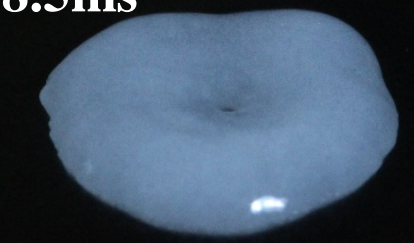

$10.2 \mathrm{~ms}$

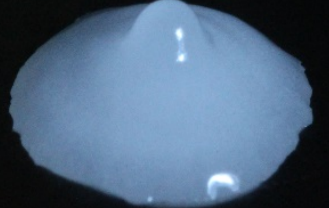

$0.9 \mathrm{~ms}$

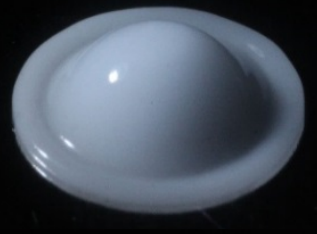

$2.7 \mathrm{~ms}$



\section{$4.7 \mathrm{~ms}$}

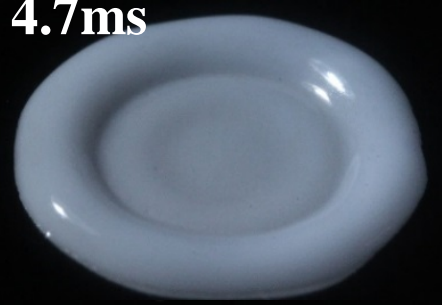

$6.7 \mathrm{~ms}$

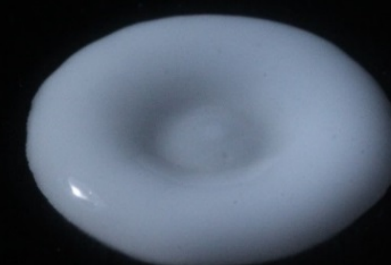

$8.7 \mathrm{~ms}$



$10.7 \mathrm{~ms}$

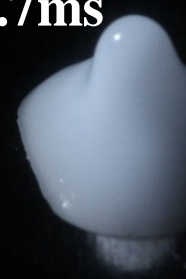

(b) $T_{w}=170{ }^{\circ} \mathrm{C}$

\section{$1.2 \mathrm{~ms}$}
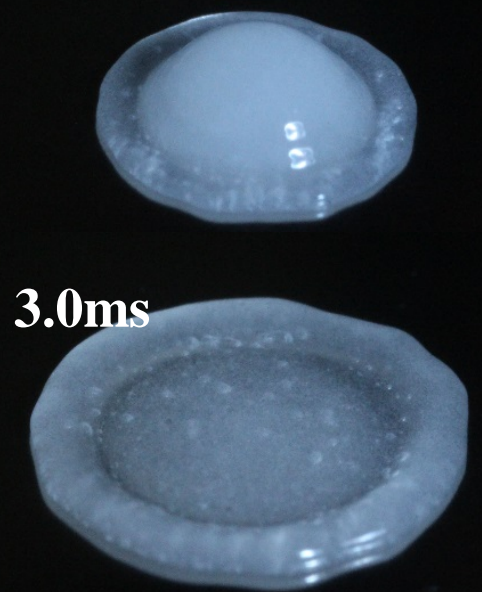

$5.0 \mathrm{~ms}$

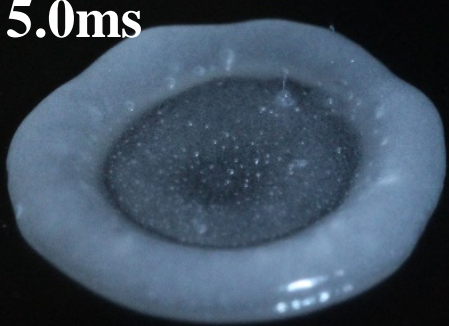

\section{$7.2 \mathrm{~ms}$}

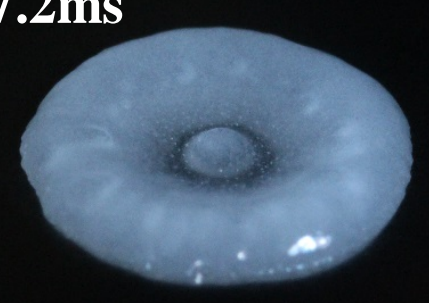

$8.7 \mathrm{~ms}$

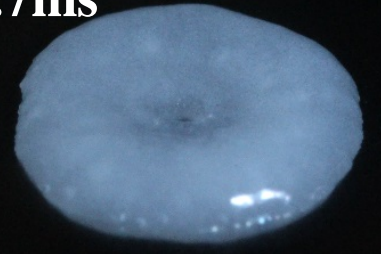

$10.3 \mathrm{~ms}$

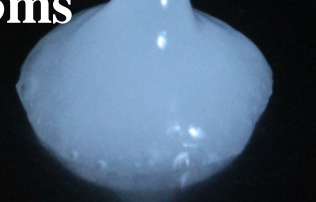

$5 \mathrm{~mm}$

$5 \mathrm{wt} \%$ emulsion

\section{$0.8 \mathrm{~ms}$}

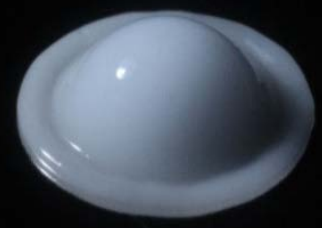

2.9ms

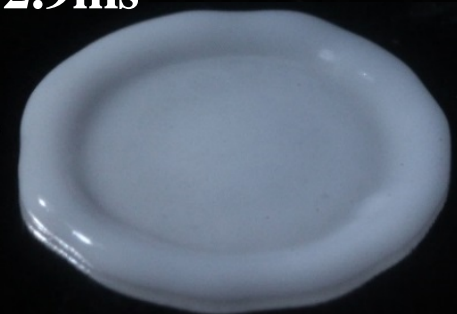

4.9ms
$5 \mathrm{~mm}$

$5 \mathrm{wt} \%$ emulsion

$15 \mathrm{wt} \%$ emulsion

$6.9 \mathrm{~ms}$

8.9ms

$10.9 \mathrm{~ms}$
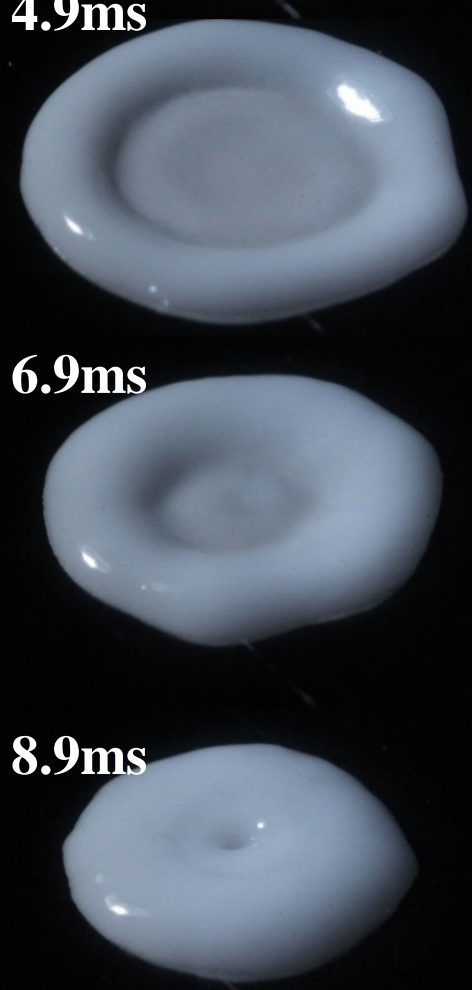

15 wt\% emulsion

Fig.6(a),(b) Fujimoto et al. 

(c) $T_{w}=230{ }^{\circ} \mathrm{C}$

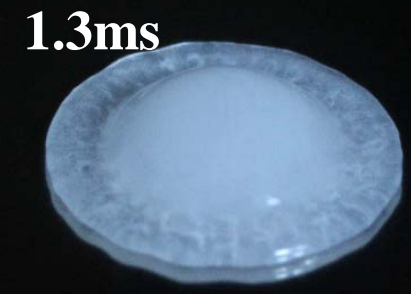

\section{1ms}
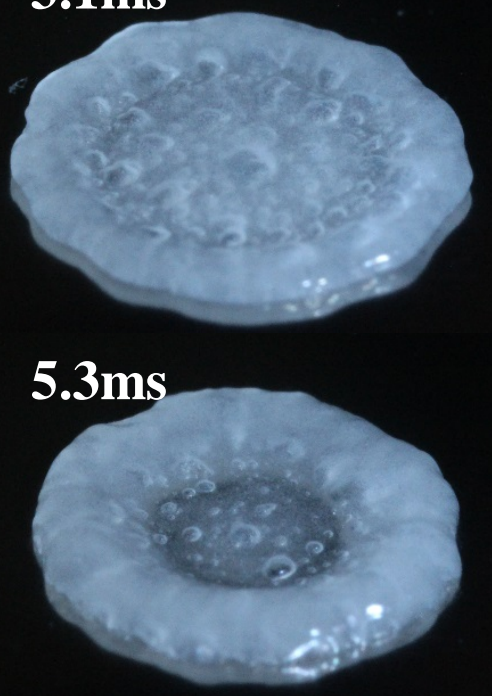

$6.7 \mathrm{~ms}$
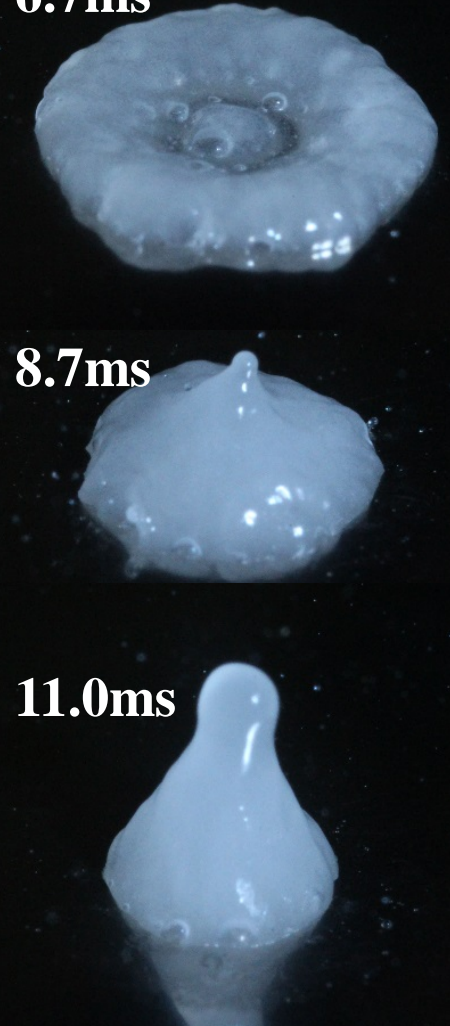

$5 \mathrm{~mm}$

$5 \mathrm{wt} \%$ emulsion (d) $T_{w}=290{ }^{\circ} \mathrm{C}$

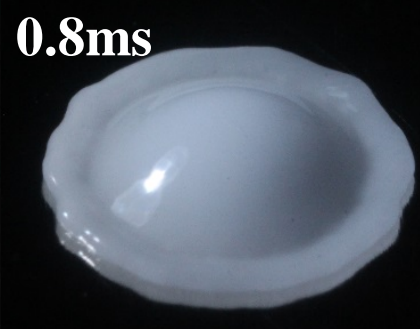

$1.1 \mathrm{~ms}$

\section{$0.9 \mathrm{~ms}$}

\section{$2.8 \mathrm{~ms}$}

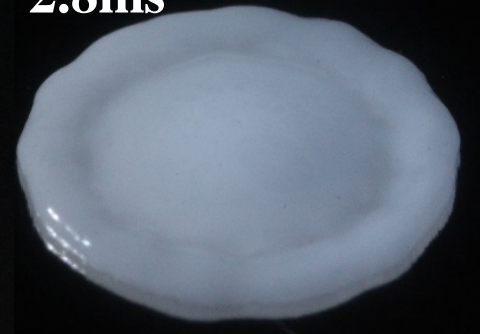

$4.8 \mathrm{~ms}$



$6.9 \mathrm{~ms}$

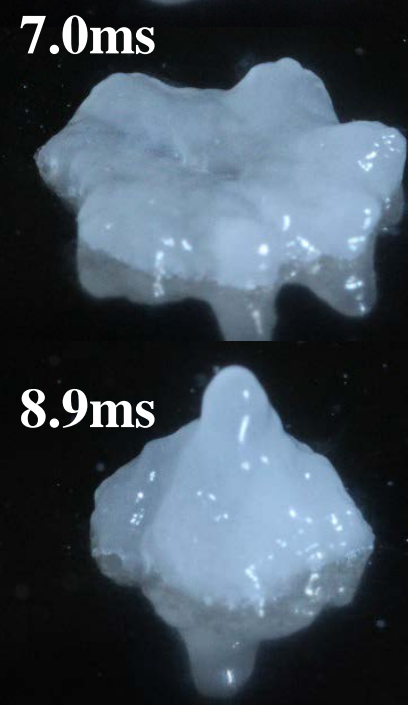

\section{$3.0 \mathrm{~ms}$}

$3.0 \mathrm{~ms}$

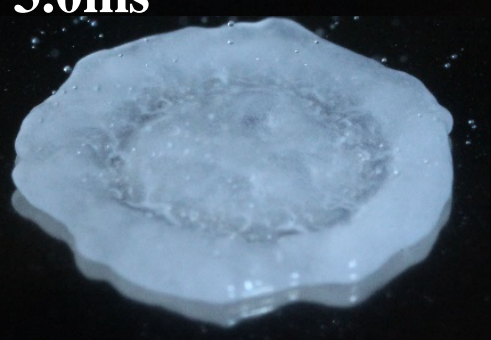

$4.8 \mathrm{~ms}$

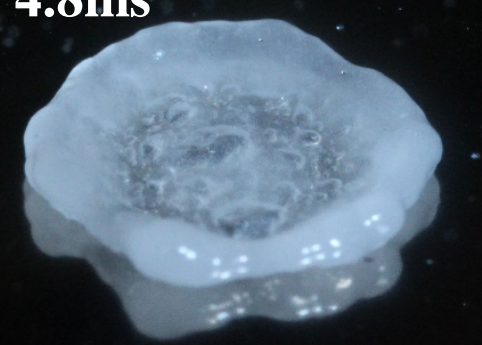

$4.9 \mathrm{~ms}$

$11.2 \mathrm{~ms}$

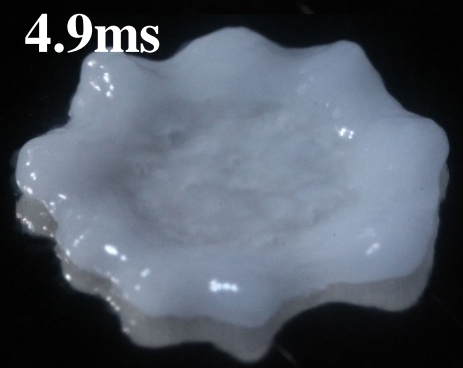

\section{$7.0 \mathrm{~ms}$}

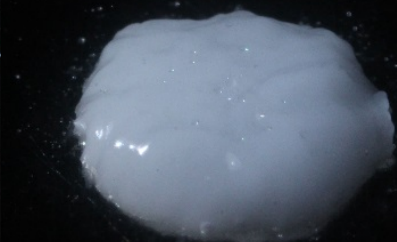

8.6ms

$10.7 \mathrm{~ms}$

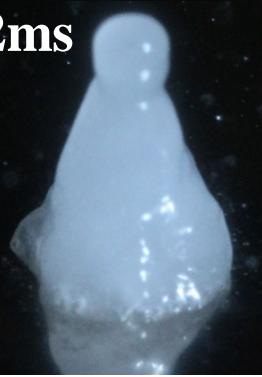

$11.0 \mathrm{~ms}$

\section{$5 \mathrm{~mm}$}

$5 \mathrm{wt} \%$ emulsion $15 \mathrm{wt} \%$ emulsion

Fig.6(c),(d) Fujimoto et al. 
(e) $T_{w}=380{ }^{\circ} \mathrm{C}$

\section{$1.6 \mathrm{~ms}$}



$3.6 \mathrm{~ms}$

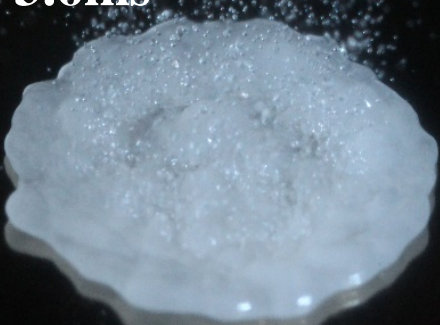

$5.4 \mathrm{~ms}$

$9.5 \mathrm{~ms}$
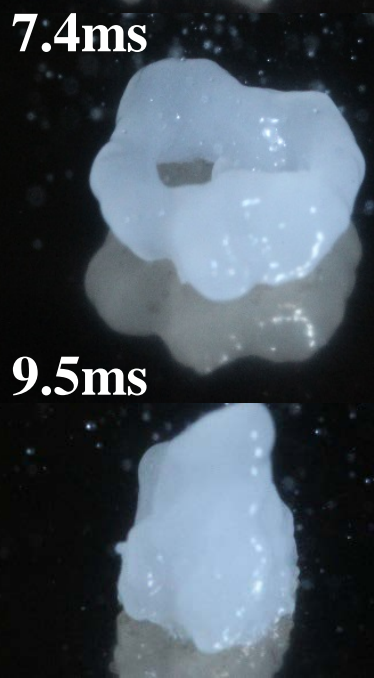

$11.7 \mathrm{~ms}$

$11.1 \mathrm{~ms}$

7.3ms

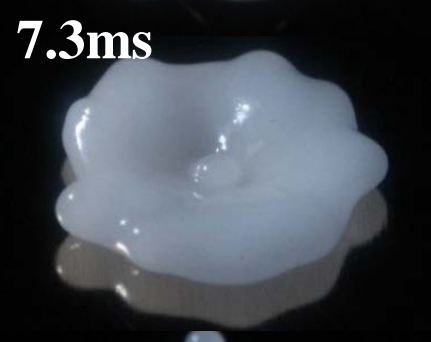

$9.1 \mathrm{~ms}$

$5 \mathrm{~mm}$

5 wt\% emulsion

\section{$1.1 \mathrm{~ms}$}

\section{$3.2 \mathrm{~ms}$}

$5.0 \mathrm{~ms}$

g.1ms
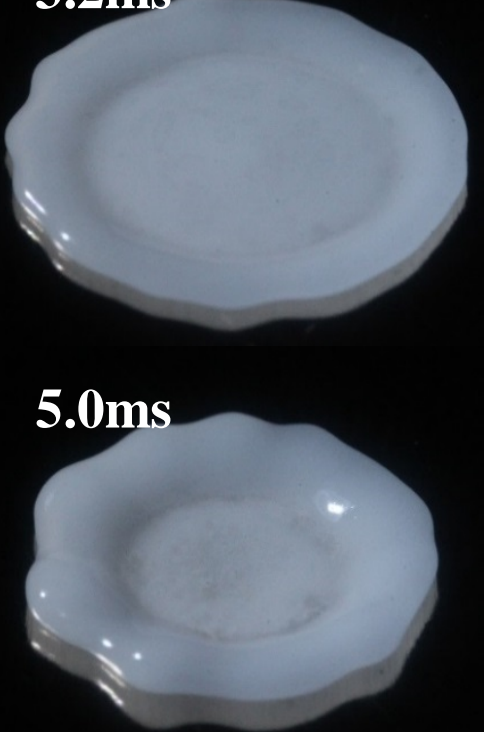

(f) $T_{w}=470{ }^{\circ} \mathrm{C}$

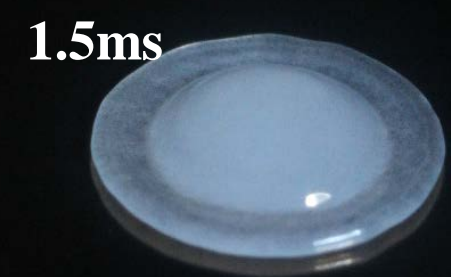

$3.4 \mathrm{~ms}$

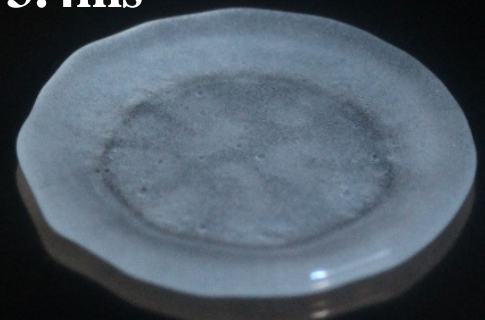

$5.4 \mathrm{~ms}$
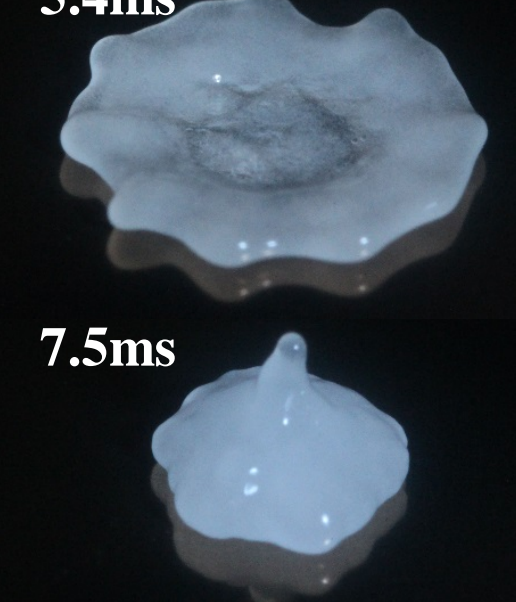

$9.0 \mathrm{~ms}$

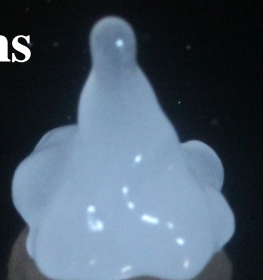

$11.5 \mathrm{~ms}$

$5.4 \mathrm{~ms}$

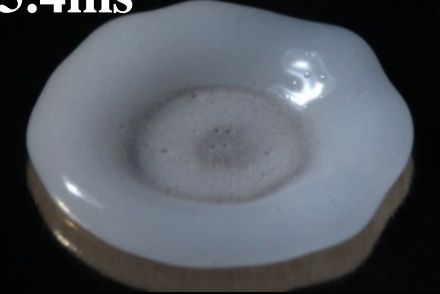

$7.4 \mathrm{~ms}$

$3.3 \mathrm{~ms}$

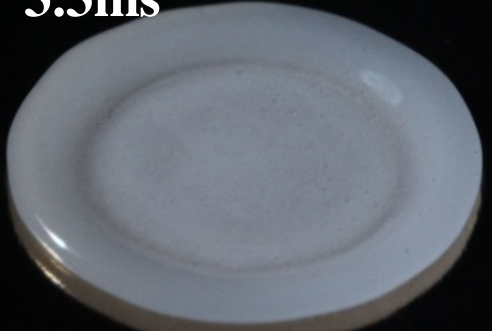

.4ns
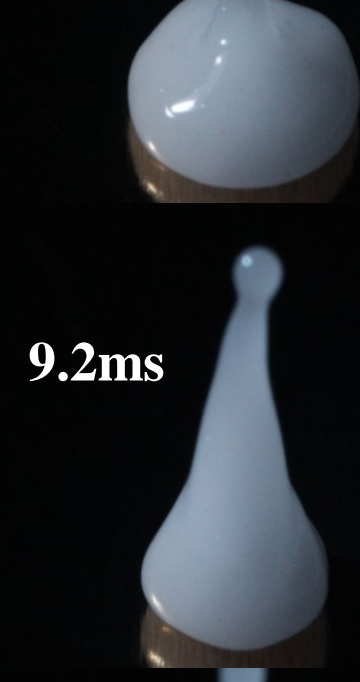

$11.4 \mathrm{~ms}$
$5 \mathrm{~mm}$

$5 \mathrm{wt} \%$ emulsion $15 \mathrm{wt} \%$ emulsion

Fig.6(e),(f) Fujimoto et al. 
(a) $T_{w}=290{ }^{\circ} \mathrm{C}$

$0.9 \mathrm{~ms}$
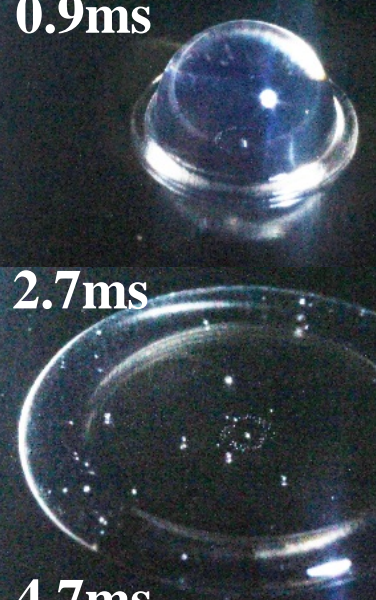

$4.7 \mathrm{~ms}$

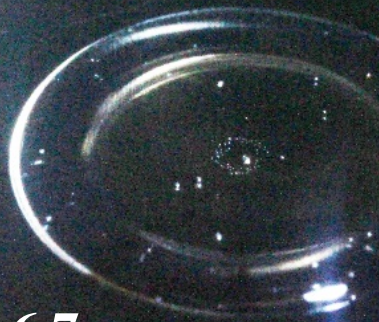

\section{$6.7 \mathrm{~ms}$}

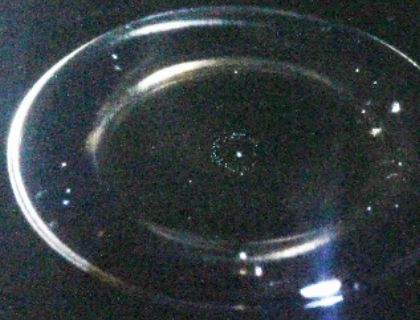

$8.7 \mathrm{~ms}$

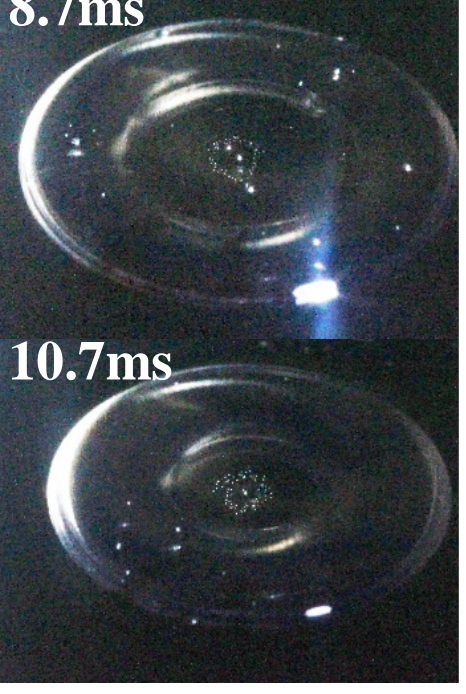

$5 \mathrm{~mm}$ (b) $T_{w}=380{ }^{\circ} \mathrm{C}$

$0.8 \mathrm{~ms}$
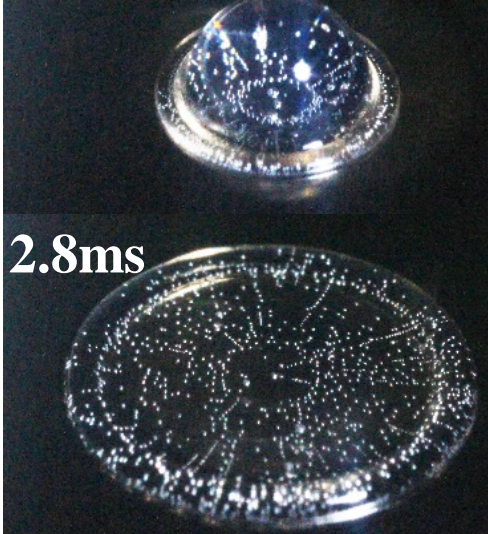

\section{$4.8 \mathrm{~ms}$}

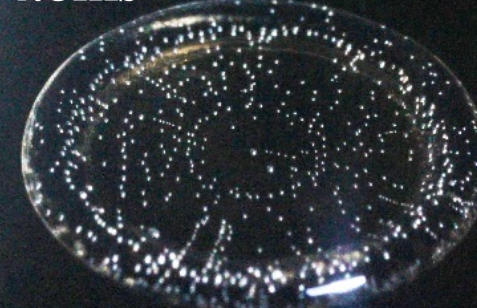

$6.9 \mathrm{~ms}$

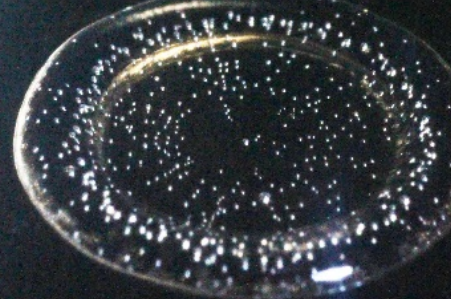

8.6ms

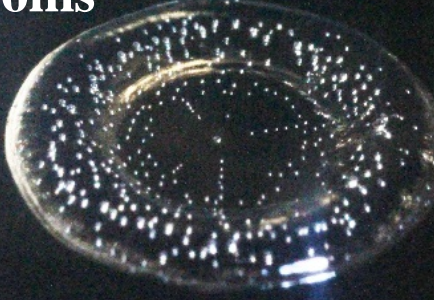

$10.7 \mathrm{~ms}$

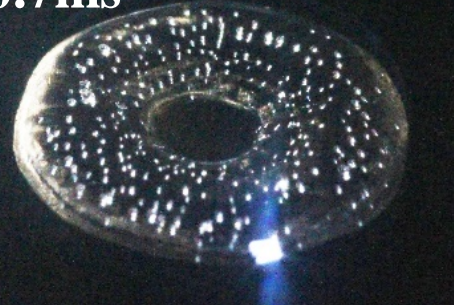

$5 \mathrm{~mm}$ (c) $T_{w}=440{ }^{\circ} \mathrm{C}$

\section{$0.9 \mathrm{~ms}$}

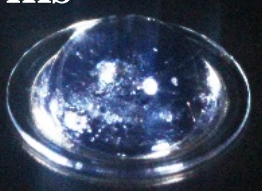

$3.0 \mathrm{mc}$

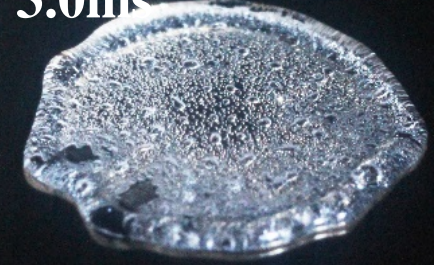

$4.9 \mathrm{~ms}$

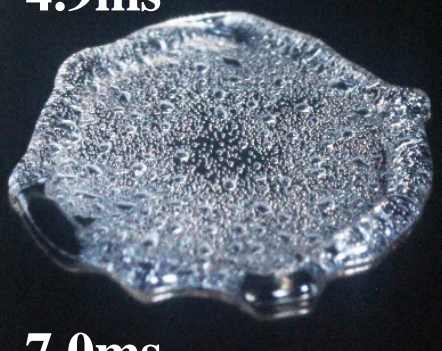

\section{$7.0 \mathrm{~ms}$}

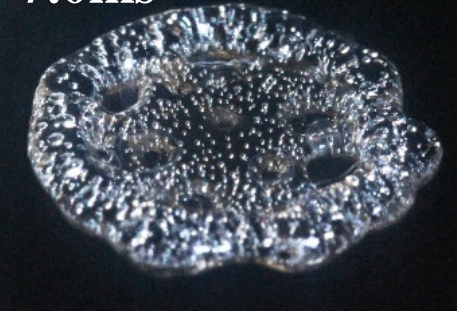

\section{$8.9 \mathrm{~ms}$}

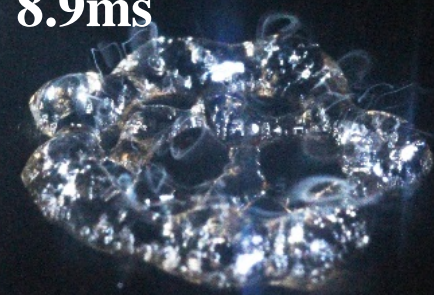

\section{$11.0 \mathrm{~ms}$}

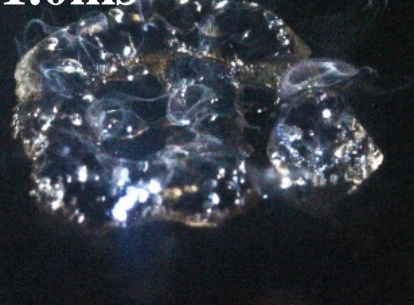

$5 \mathrm{~mm}$ (d) $T_{w}=470{ }^{\circ} \mathrm{C}$

$1.1 \mathrm{~ms}$
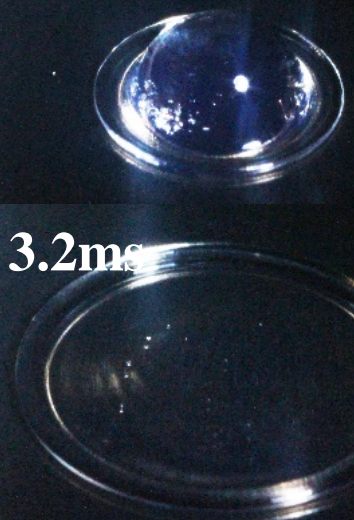

$5.0 \mathrm{~ms}$
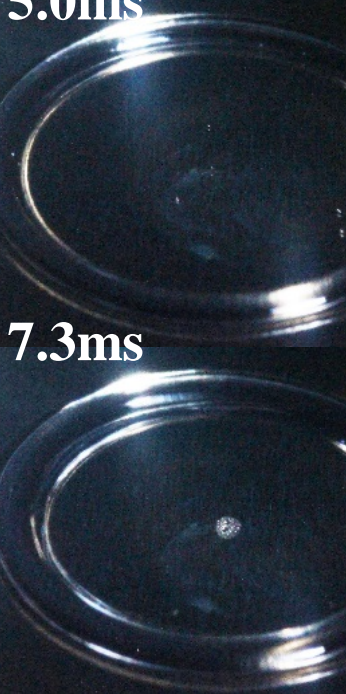

$9.1 \mathrm{~ms}$

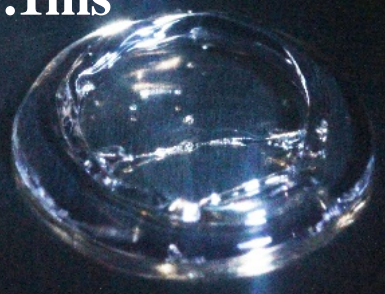

$11.1 \mathrm{~ms}$

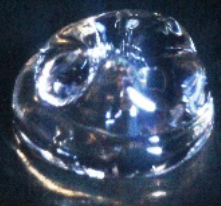

$5 \mathrm{~mm}$ 


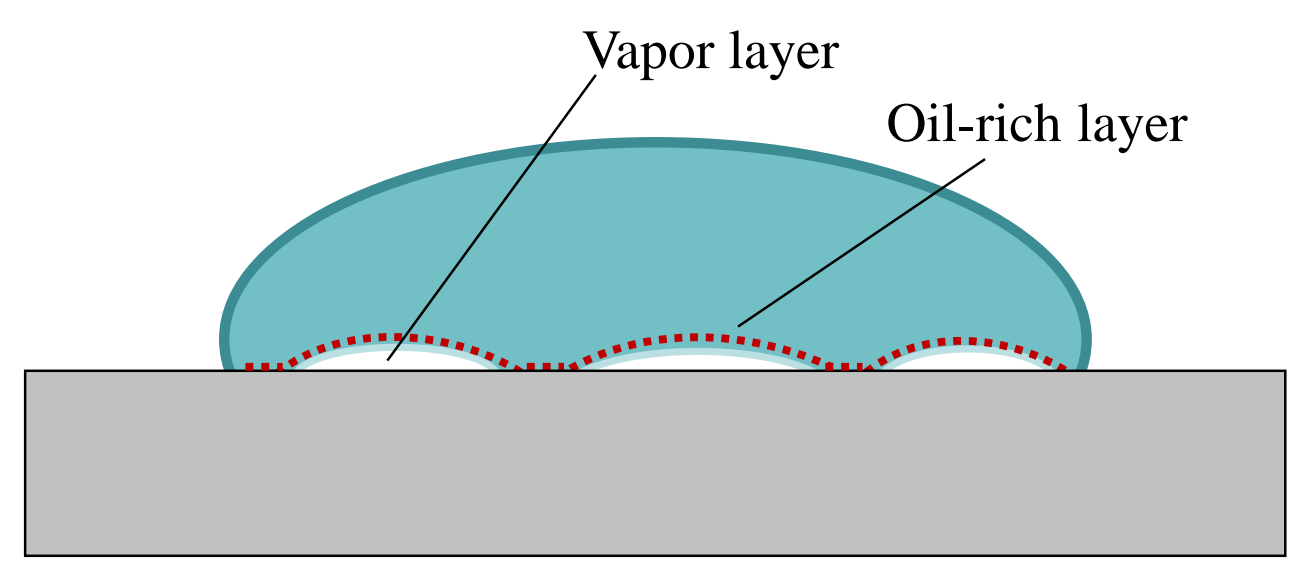

Fig. 8 Fujimoto et al. 


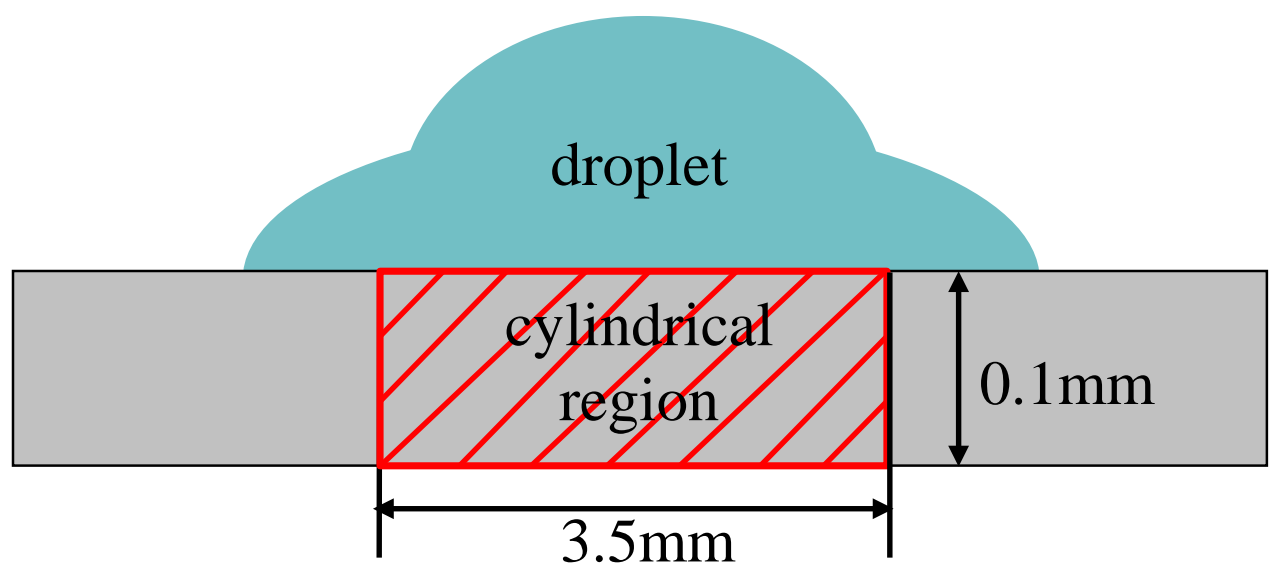

Fig. 9 Fujimoto et al. 


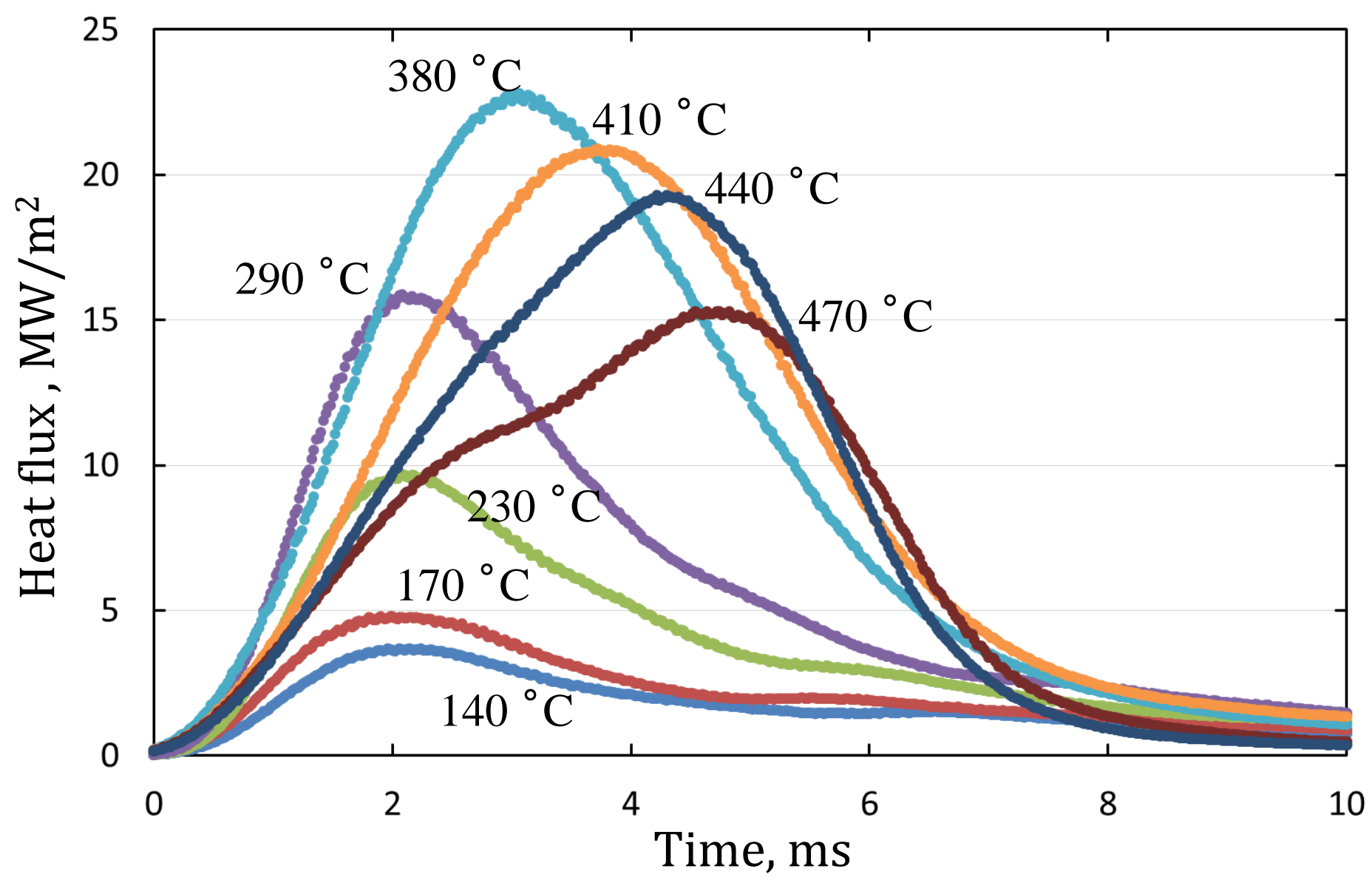

Fig. 10 Fujimoto et al. 


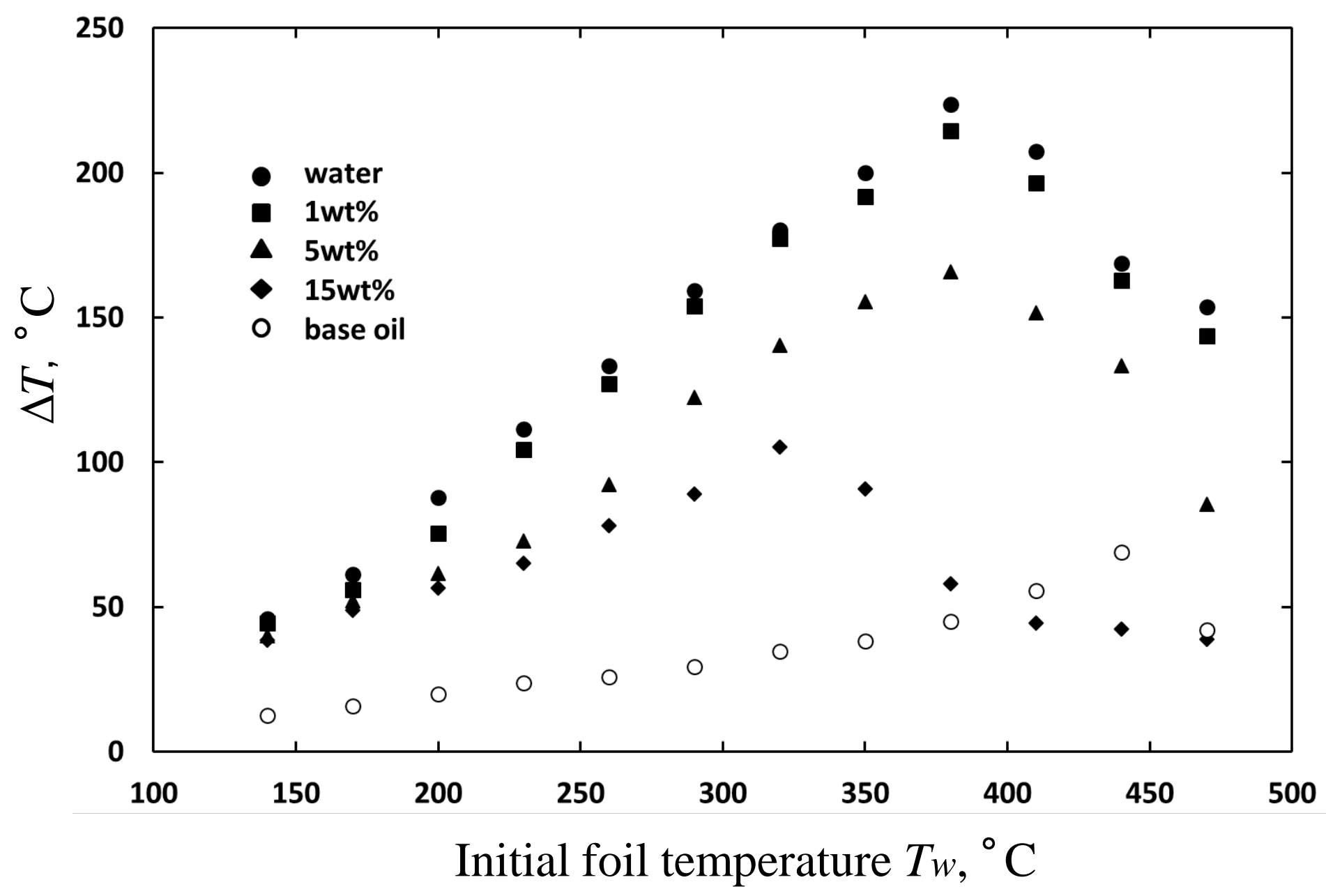

Fig. 11 Fujimoto et al. 


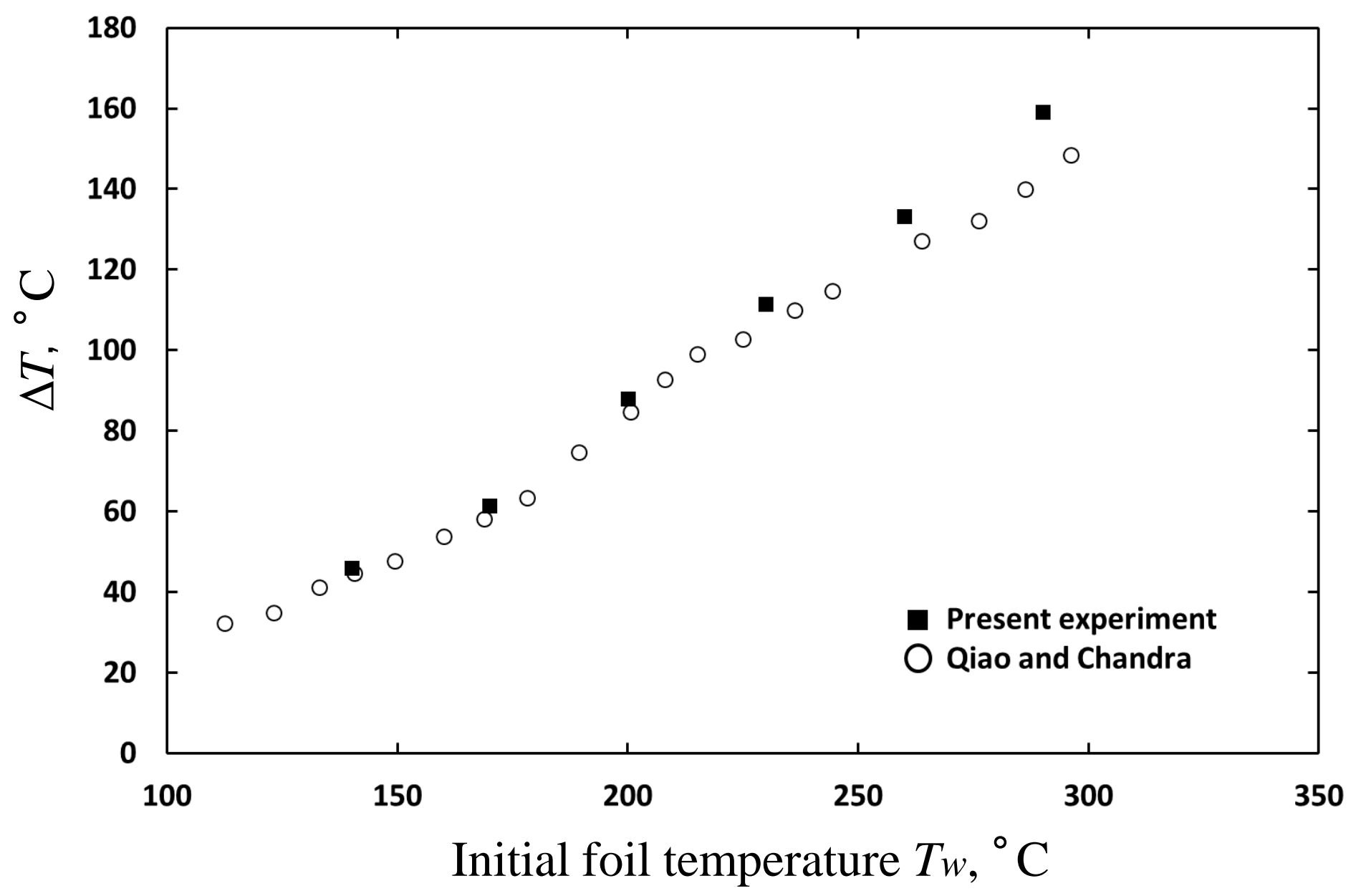

Fig. 12 Fujimoto et al. 
Table. 1 Fujimoto et al.

\begin{tabular}{|c|c|c|c|c|c|}
\hline $\begin{array}{c}\text { Setup } \\
\text { concentration }\end{array}$ & $\begin{array}{c}\text { Surface } \\
\text { tension } \\
\left(10^{-2} \mathrm{~N} / \mathrm{m}\right)\end{array}$ & $\begin{array}{c}\text { Viscosity } \\
\left(10^{-3} \text { Pas }\right)\end{array}$ & $\begin{array}{c}\text { Specific } \\
\text { heat } \\
\left(10^{3} \mathrm{~J} / \mathrm{kgK}\right)\end{array}$ & $\begin{array}{c}\text { Thermal } \\
\text { conductivity } \\
(\mathrm{W} / \mathrm{mK})\end{array}$ & $\begin{array}{c}\text { Density } \\
10^{3}\left(\mathrm{~kg} / \mathrm{m}^{3}\right)\end{array}$ \\
\hline water & 7.28 & 1.00 & 4.18 & 0.598 & 1.00 \\
\hline $1.0 \mathrm{wt} \%$ & 3.55 & 1.10 & 4.16 & 0.598 & 1.00 \\
\hline $5.0 \mathrm{wt} \%$ & 3.55 & 1.62 & 4.06 & 0.579 & 1.00 \\
\hline $15.0 \mathrm{wt} \%$ & 3.42 & 2.98 & 3.83 & 0.534 & 0.98 \\
\hline base oil & 3.13 & 14.4 & 1.85 & 0.144 & 0.88 \\
\hline
\end{tabular}

